\title{
delta-Melt: Nucleic acid conformational penalties from melting experiments
}

Atul Rangadurai ${ }^{1 \#}$, Honglue Shi ${ }^{2 \#}, \mathrm{Yu} \mathrm{Xu}^{2 \#}$, Bei Liu ${ }^{1}$, Hala Abou Assi ${ }^{1}$, Huiqing Zhou ${ }^{1,3}$, Isaac J. Kimsey ${ }^{1,4}$, and Hashim M. Al-Hashimi ${ }^{1,2 *}$

1. Department of Biochemistry, Duke University School of Medicine, Durham, NC, USA

2. Department of Chemistry, Duke University, Durham, NC, USA

Present Address:

3. Department of Chemistry, Boston College, Boston, MA, USA

4. Nymirum, 4324 S. Alston Avenue, Durham, NC, USA

${ }^{\#}$ These authors contributed equally to this work

${ }^{*}$ To whom correspondence should be addressed:

hashim.al.hashimi@duke.edu

Tel: 919-660-1113 


\section{Abstract}

Thermodynamic propensities of biomolecules to adopt non-native conformations are crucial for understanding how they function, but prove difficult to measure experimentally. Combining optical melting experiments with chemical modifications and mutations, we developed delta-Melt for measuring the energetic penalties associated with nucleic acid conformational rearrangements and how they vary with sequence and physiological conditions. delta-Melt is fast, simple, cost effective, and can characterize conformational penalties inaccessible to conventional biophysical methods. 


\section{Main text}

The biological functions of nucleic acids often require changes in structure that occur in response to binding of proteins, ligands, and other nucleic acids, as well as changes in physiological conditions ${ }^{1}$. Changing the conformation of a biomolecule upon binding to a partner molecule comes with an energetic cost or penalty which has to be paid by favorable intermolecular interactions ${ }^{2}$. Although widespread in biology, and central to molecular recognition, we know very little about the magnitude of these conformational penalties and to what extent they determine binding affinity and specificity $^{2,3}$. This is in part due to challenges in experimentally measuring these conformational penalties, which requires accurately measuring the population of a minor $(<10 \%)$ conformation amongst thousands of conformations in an ensemble.

Recent developments in NMR relaxation dispersion (RD) techniques ${ }^{4}$ have made it possible to accurately quantify the population of minor conformations and to deduce the conformational penalties accompanying their formation (Fig. 1a). Despite their success, these NMR-based approaches are technically demanding, laborious, expensive, and require the preparation of large quantities of isotopically enriched samples. Therefore, they do not lend themselves to high throughput investigations to comprehensively explore how conformational penalties vary with sequence, posttranscriptional modifications, and other physiological conditions. They are also limited to minor conformations with populations $>0.01 \%$ and transitions on the micro-to-milli second timescales.

To address these limitations, we developed a new approach we call "delta-Melt" to measure conformational penalties in nucleic acids. delta-Melt combines two widely 
used and simple techniques in molecular biology, melting experiments ${ }^{5}$ and perturbations in the form of mutations or chemical modifications. In delta-Melt, a mutation or chemical modification is introduced so as to substantially bias (>90\%) the conformational ensemble to the desired $\mathrm{i}^{\text {th }}$ minor conformation for which we wish to determine a conformational penalty $\Delta \mathrm{G}_{\text {conf }}^{\circ}(\mathrm{i})$ (Fig. 1b). The unmodified wild-type (WT) and mutated/chemically modified (Mut) nucleic acids are then subjected to melting experiments to measure the difference between their melting energetics $\Delta \Delta \mathrm{G}_{\text {melt }}^{\circ}(\mathrm{i})=$ $\Delta \mathrm{G}_{\text {melt,WT }}^{\circ}-\Delta \mathrm{G}_{\text {melt,Mut }}^{\circ}$ (Fig. 1c). The desired $\Delta \mathrm{G}_{\text {conf }}^{\circ}(\mathrm{i})$ value is then given by the difference in melting energetics plus an offset $c(i)\left(\Delta G_{\text {conf }}^{\circ}(i)=\Delta \Delta G_{\text {melt }}^{\circ}(i)+\right.$ c(i)), which accounts for any changes in energetic stability of the single-stranded and the $i^{\text {th }}$ conformation due to the mutation/modification $\left(\mathrm{c}(\mathrm{i})=\Delta \Delta \mathrm{G}_{\mathrm{ss}(\mathrm{mut}-\mathrm{WT})}^{\circ}\right.$ $\Delta \Delta \mathrm{G}_{\mathrm{i}(\mathrm{mut}-\mathrm{WT})}^{\circ}$ ) (Fig. 1d). Assuming that $\mathrm{c}(\mathrm{i})$ does not vary with sequence and conditions, it can be estimated via calibration with a few $\Delta \mathrm{G}_{\text {conf }}^{\circ}(\mathrm{i})$ data points measured independently using NMR or any other appropriate technique, as outlined in Fig. 1d. Following calibration, $\Delta \mathrm{G}_{\text {conf }}^{\circ}(\mathrm{i})$ can then be estimated using a pair of melting experiments $\left(\Delta \mathrm{G}_{\text {conf }}^{\circ}(\mathrm{i}) \sim \Delta \Delta \mathrm{G}_{\text {delta-Melt }}^{\circ}(\mathrm{i})=\Delta \Delta \mathrm{G}_{\text {melt }}^{\circ}(\mathrm{i})+\mathrm{c}(\mathrm{i}) \quad\right), \quad$ allowing facile measurements of nucleic acid conformational penalties over a variety of sequences and/or physiological conditions. In theory, unlike NMR and other techniques, delta-Melt has no limit on the population and lifetime of the minor conformation and the size of biomolecules that can be examined. However, delta-Melt does not provide any information regarding the kinetics of interconversion, and the analysis might prove difficult for certain molecules that exhibit multiple melting transitions. 


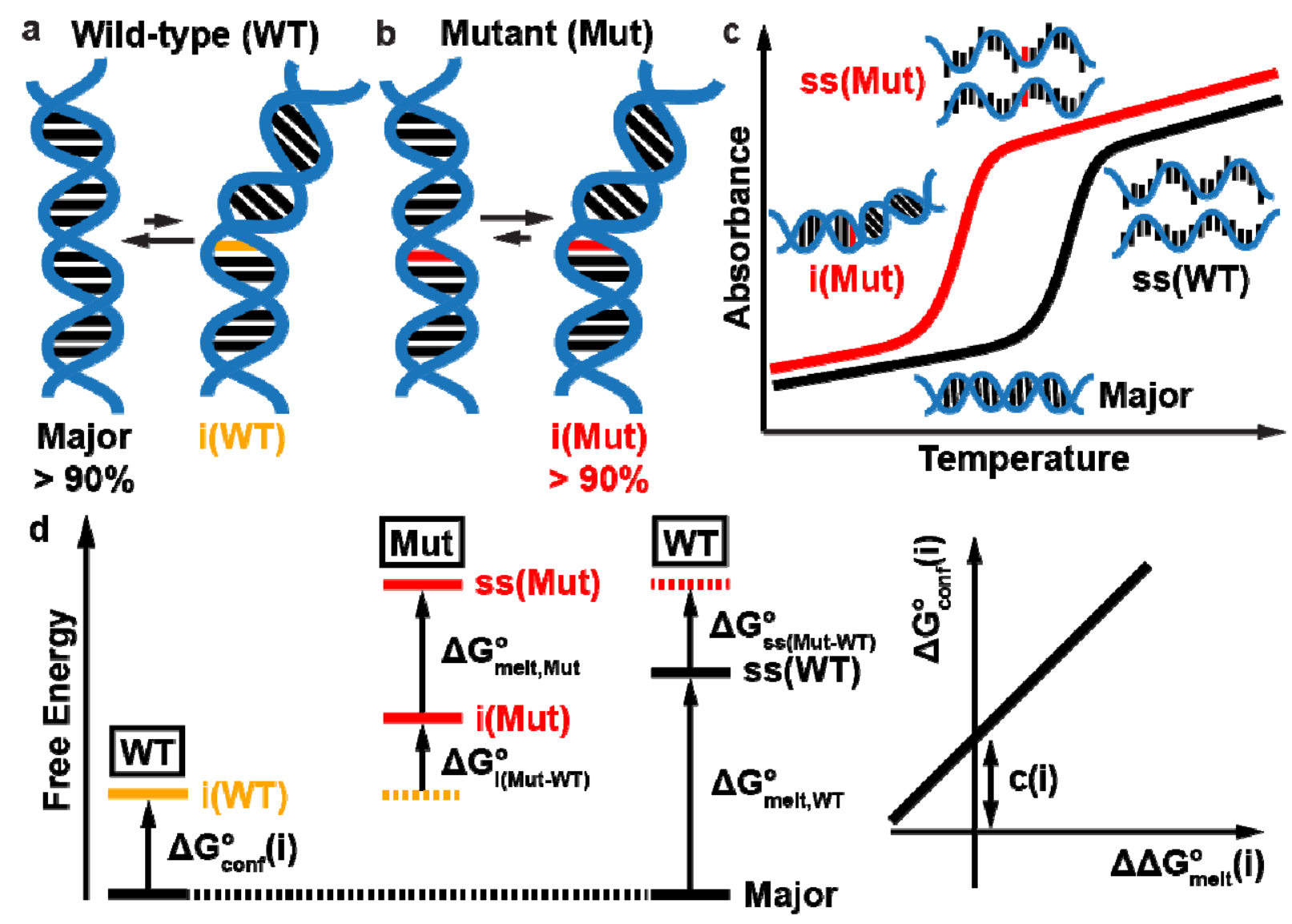

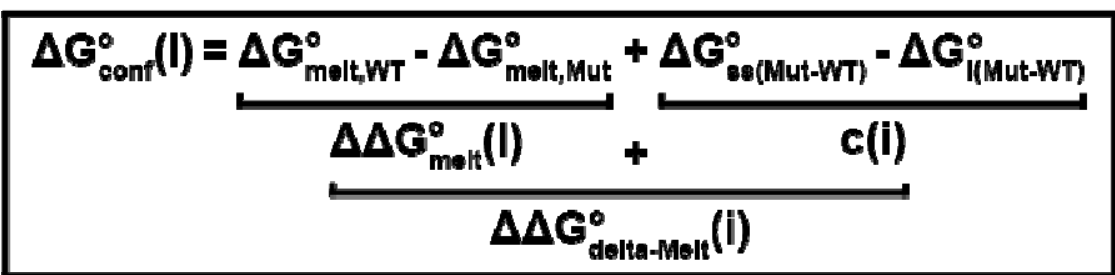

Fig. 1. The delta-Melt approach for measuring nucleic acid conformational penalties. (a) Dynamic equilibrium between the major and $\mathrm{i}^{\text {th }}$ minor conformation of the wild-type (WT) nucleic acid. Orange indicates a change in the conformation of a base pair when forming the $\mathrm{i}^{\text {th }}$ minor conformation. (b) Chemical modifications or mutations (red) are introduced (Mut) to bias the conformational ensemble towards the $\mathrm{i}^{\text {th }}$ minor conformation of the WT nucleic acid. (c) Schematic diagram showing optical melting experiments on WT (black) and Mut (red) nucleic acids. (d) Free energy diagram of delta-Melt (left), relationship between the free energies in delta-Melt (bottom) and expected correlation between and (right). 
As an initial test, we used delta-Melt to measure the conformational penalty associated with opening Watson-Crick A-T base pairs (bps) in DNA. Base opening is the elementary step that drives melting and annealing of nucleic acids, and their unwinding by helicases ${ }^{6}$. Measurements of imino proton exchange rates $^{7}$ have shown that Watson-Crick A-T bps transiently open to form exceptionally low-populated (population 0.001\%) and short-lived (lifetime 0.1 $\mu$ s) conformations (Fig. 2a).

We hypothesized that substitution of $T$ by $N^{3}$-methylated thymine $\left(\mathrm{m}^{3} \mathrm{~T}\right)$, in which the imino proton of thymine is replaced by a methyl group to disrupt the $A(N 1)-T(H 3)$ hydrogen bond, could be used to substantially bias the conformational ensemble towards the minor base-open conformation ${ }^{8}$ (Fig. 2a). Indeed, NMR spectra (Extended Data Fig. 1) revealed that the modification disrupts the targeted bp with the $\mathrm{m}^{3} \mathrm{~T}$ residue being intra-helical.

Optical melting experiments were used to measure the energetics of duplex melting with or without $\mathrm{m}^{3} \mathrm{~T}$ substitution at ten sites corresponding to six different trinucleotide sequence contexts (Supplementary Table 1, Extended Data Figs. 2 and 3). As expected, the differences between the energetics of melting $\left(\Delta \Delta \mathrm{G}_{\text {melt }}^{\circ}(\mathrm{i})=\Delta \mathrm{G}_{\text {melt }, \mathrm{A}-\mathrm{T}}\right.$ - $\Delta \mathrm{G}_{\text {melt,A-m3T }}^{\circ}$ ) were linearly correlated (Fig. 2b) $(r=0.91, R M S E=0.3 \mathrm{kcal} / \mathrm{mol}$ ) to the conformational penalties for base opening measured independently using NMR (Methods, Supplementary Note 1, Extended Data Figs. 4 and 5, and Supplementary Tables 2-4). These results provide a proof of concept for delta-Melt, demonstrate its utility to map the conformational penalty of $A-T$ base opening across different sequence contexts, and also establish $\mathrm{A}-\mathrm{m}^{3} \mathrm{~T}$ as a mimic of the elusive base open state. 
a

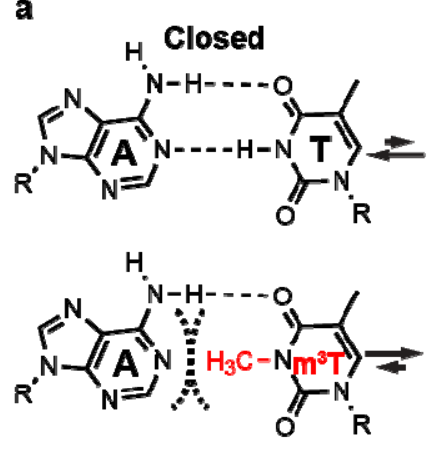

C Watson-Crick

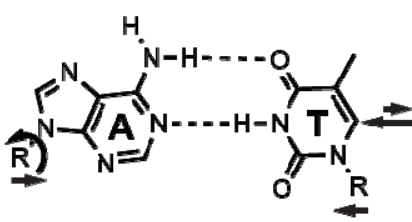

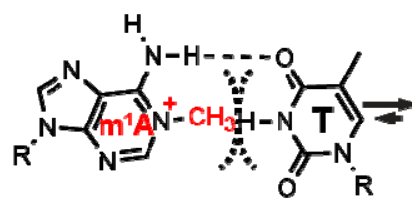

e

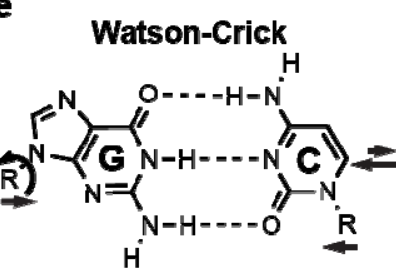

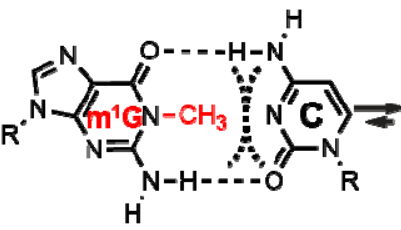

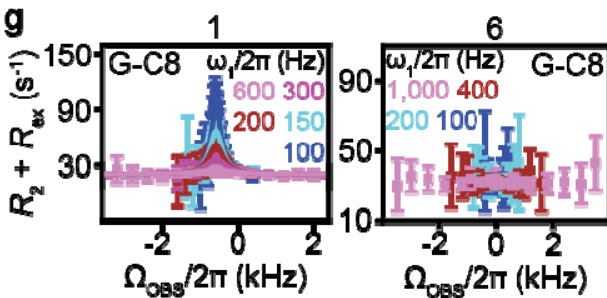

C-C Hoogsteen predlctlons

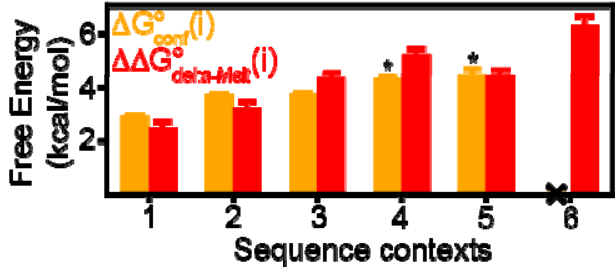

A-T opening
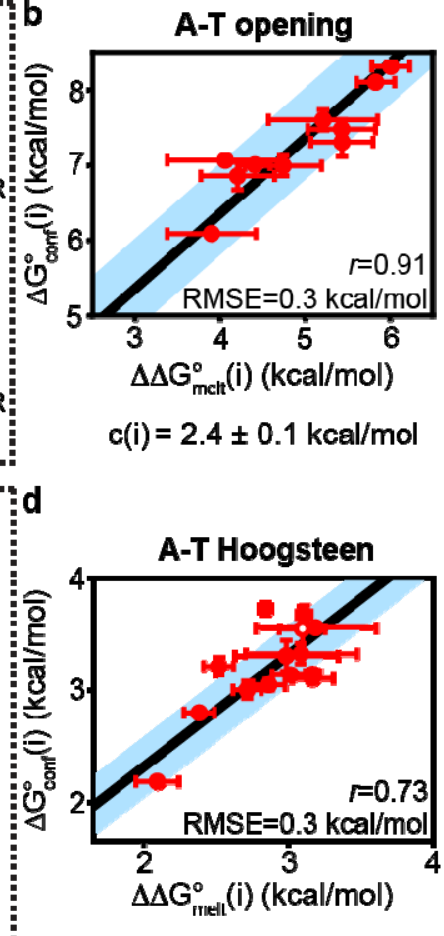

$c(i)=0.3 \pm 0.1 \mathrm{kcal} / \mathrm{mol}$

Hoogsteen

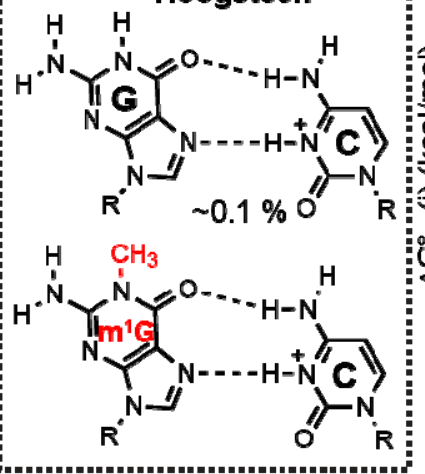

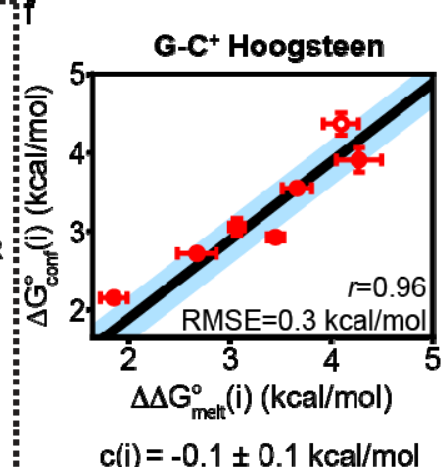

$c(i)=-0.1 \pm 0.1 \mathrm{kcal} / \mathrm{mol}$

300

HG1

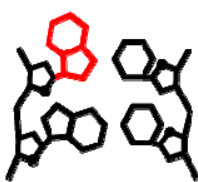

$\mathrm{HG} 2$ $\Delta \Delta G_{\text {meth }}^{\circ}(H G 1)+\Delta \Delta G_{\text {meth }}^{\circ}(H G 2)-\Delta \Delta G_{\text {melt }}^{\circ}(H G 1+2)$

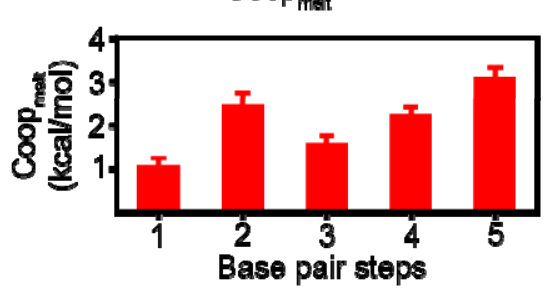


Fig. 2. Applications of delta-Melt to measure conformational penalties in DNA. (a) Dynamic equilibrium between closed and open states of the A-T bps in which the T-H3 proton is susceptible to solvent exchange (blue lightning). Biasing the conformational ensemble toward the open state using $\mathrm{m}^{3} \mathrm{~T}$. (b) Correlation plot between $\Delta \mathrm{G}_{\text {conf }}^{\circ}(\mathrm{i})$ and $\Delta \Delta \mathrm{G}_{\text {melt }}^{\circ}(\mathrm{i})$ for $\mathrm{A}-\mathrm{T}$ base opening (raw data and constructs in Extended Data Figs. 2-5 and Supplementary Tables 1-4). (c,e) Dynamic equilibrium between WatsonCrick and Hoogsteen conformations in A-T (c) and G-C (e) bps. Biasing the conformational ensemble toward the Hoogsteen conformation using $N^{1}$-methylated purines. (d,f) Correlation plot between $\Delta \mathrm{G}_{\text {conf }}^{\circ}(\mathrm{i})$ and $\Delta \Delta \mathrm{G}_{\text {melt }}^{\circ}(\mathrm{i})$ for $\mathrm{A}-\mathrm{T}$ (d) and G-C $\mathrm{C}^{+}$Hoogsteen bps (f) (raw data and constructs in Extended Data Figs. 24 and 6-7, and Supplementary Tables 1 and 5-7). (g) (Bottom) Comparison of measured G-C $\mathrm{C}^{+}$ Hoogsteen penalties using NMR (orange) and values measured using delta-Melt (red) (raw data and constructs in Extended Data Figs. 2-3 and 6-8, and Supplementary Tables 1 and 5-8). Lower-confidence data points (Methods) obtained from weak $R_{1 \rho}$ RD profiles are denoted using “*”. Data point 6 with a flat $R_{1 \rho} \mathrm{RD}$ profile is denoted using " $\mathrm{x}$ ", indicating that the minor conformation in this case falls outside the detection limit. (Top) Representative examples of $R_{1 \rho}$ RD profiles showing the measured effective transverse relaxation rate $\left(R_{2}+R_{\mathrm{ex}}\right)$ as function of offset $\left(\Omega_{\mathrm{OBS}} / 2 \pi\right)$ and color-coded spin-lock power $\left(\omega_{1} / 2 \pi\right)$ (Methods). Errors bars were obtained by propagating the uncertainty in $R_{1 \rho}$ as described in Methods. (h) Estimate of cooperativity of Hoogsteen bp formation using delta-Melt (Coop melt $)$ for different bp steps (Methods, raw data and constructs Extended Data Figs. 3 and 9, and Supplementary Tables 1 and 9). Errors in Coop $_{\text {melt }}$ were determined by propagating the uncertainties from the UV melts as described in Methods. Black dashed curves in panels a, $c$ and e denote steric clashes. For panels b, $d, f$ and g, error bars for NMR and delta-Melt measurements were obtained using a Monte-Carlo scheme as described in Methods, and by propagating the uncertainties from UV melts (and c(i) for panel g), respectively, as described in Methods. Pearson's correlation coefficient $(r)$ and root mean square error (RMSE), were computed as described in Methods. Blue shaded region denotes estimate of error of linear regression obtained using Monte-Carlo simulations, while open symbols denote data derived from weak RD profiles (Methods). 
As a second test, we used delta-Melt to measure the conformational penalty associated with the Watson-Crick to Hoogsteen transition in duplex DNA (Fig. 2c, e) ${ }^{9}$. In this conformational transition, the purine base flips $180^{\circ}$ about the glycosidic bond to adopt a syn conformation, and this is accompanied by constriction of the DNA backbone to allow hydrogen bonding between the bases (Fig. 2c, e) ${ }^{10}$. The conformational penalty associated with forming Hoogsteen bps is proposed to play important roles in DNA-protein recognition ${ }^{2,11}$ and in DNA damage induction ${ }^{12}$. Using NMR RD $^{4}$, Hoogsteen bps have been shown to form transiently in naked DNA duplexes with populations of $\sim 0.5 \%(A-T)$ and $\sim 0.1 \%\left(G-C^{+}\right)$, and with lifetimes of $\sim 1$ millisecond ${ }^{9}$.

We previously showed that $N^{1}$-methylated adenine $\left(m^{1} A\right)$ and $N^{1}$-methylated guanine $\left(\mathrm{m}^{1} \mathrm{G}\right)$ can be used to substantially bias the conformational ensemble towards the minor A-T and G-C ${ }^{+}$Hoogsteen bps, respectively ${ }^{9,13}$ (Fig. 2c, e). Optical melting experiments were used to measure the energetics of duplex melting with and without $m^{1} A$ or $m^{1} G$ substitutions at nine sites in six duplexes, corresponding to four different trinucleotide sequence contexts, under a variety of $\mathrm{pH}$ and temperature conditions (Supplementary Table 1, Extended Data Figs. 2-3). delta-Melt was also applied to measure the Hoogsteen conformational penalties when introducing chemical modifications shown previously by NMR to perturb the minor Hoogsteen population ${ }^{14}$ (Extended Data Fig. 2).

Once again, excellent agreement was observed between the differences in melting energetics $\left(\Delta \Delta \mathrm{G}_{\text {melt }}^{\circ}(\mathrm{i})=\Delta \mathrm{G}_{\text {melt,A-T or G-C }}^{\circ}-\Delta \mathrm{G}_{\text {melt,m1A-T or m1G-C }}^{\circ}\right)$ and the corresponding conformational penalty of the Watson-Crick to Hoogsteen transition independently measured using NMR RD (Fig. 2d, f, Extended Data Figs. 4, 6 and 7, and 
Supplementary Tables 5-7) for both A-T ( $r=0.73$ and RMSE $=0.3 \mathrm{kcal} / \mathrm{mol})$ and $\mathrm{G}-\mathrm{C}$ $(r=0.96$ and $\mathrm{RMSE}=0.3 \mathrm{kcal} / \mathrm{mol})$ bps (Supplementary Note 1$)$.

Next, we tested the throughput of delta-Melt by applying it to measure the $\mathrm{G}-\mathrm{C}^{+}$ Hoogsteen conformational penalties for all sixteen trinucleotide sequence contexts in a DNA duplex that was not used for determination of calibration curves (Fig. 2g, Extended Data Figs. 3 and 8, Supplementary Table 1, Methods). To our knowledge, measurements of sequence-dependent conformational penalties in DNA have not been done so far for all trinucleotide contexts. Then, to test the accuracy of the delta-Melt derived Hoogsteen conformational penalties, we used NMR RD to independently measure these values for two trinucleotide sequence contexts, 5'-TGC-3' and 5'-CGT-3', which according to delta-Melt, have low and high penalties, respectively. These tests were performed under two different buffer conditions and three different temperatures to test the robustness of delta-Melt (Extended Data Figs. 4, 6-8, Supplementary Tables 58).

Comparison of a total of six conformational penalties measured using delta-Melt (Fig. 2g) and NMR RD revealed that it determines the Hoogsteen conformational penalties with an average accuracy of $\sim 0.5 \mathrm{kcal} / \mathrm{mol}$ (Supplementary Note 1). These results establish the throughput and accuracy of delta-Melt, including for cases which are difficult to measure reliably by NMR RD (Fig. $2 \mathrm{~g}$, data point 6). The sequencedependent Hoogsteen conformational penalties derived by delta-Melt can now be crossreferenced with sequence-dependent signatures of DNA biochemical processes ${ }^{15}$ to generate hypotheses regarding potential biological roles for Hoogsteen bps. 
Two adjacent Hoogsteen bps are often observed in X-ray structures of DNA bound to proteins and drugs ${ }^{16}$. We therefore also used delta-Melt to estimate the conformational penalty of forming a Hoogsteen bp when the neighboring bp is a preformed Hoogsteen. This allowed us to obtain insights into the cooperativity of forming tandem Hoogsteen bps (Methods). Indeed, we find that the conformational penalty associated with forming tandem Hoogsteen bps is smaller by $1-3 \mathrm{kcal} / \mathrm{mol}$ than the sum of penalties for forming two individual Hoogsteen bps for five different bp steps (Fig. 2h, Extended Data Figs. 3 and 9, Supplementary Tables 1 and 9). This indicates that tandem Hoogsteen bps can form cooperatively, as independently supported by NMR experiments on duplex DNA with preformed Hoogsteen bps ${ }^{17}$ (Extended Data Fig. 10). 

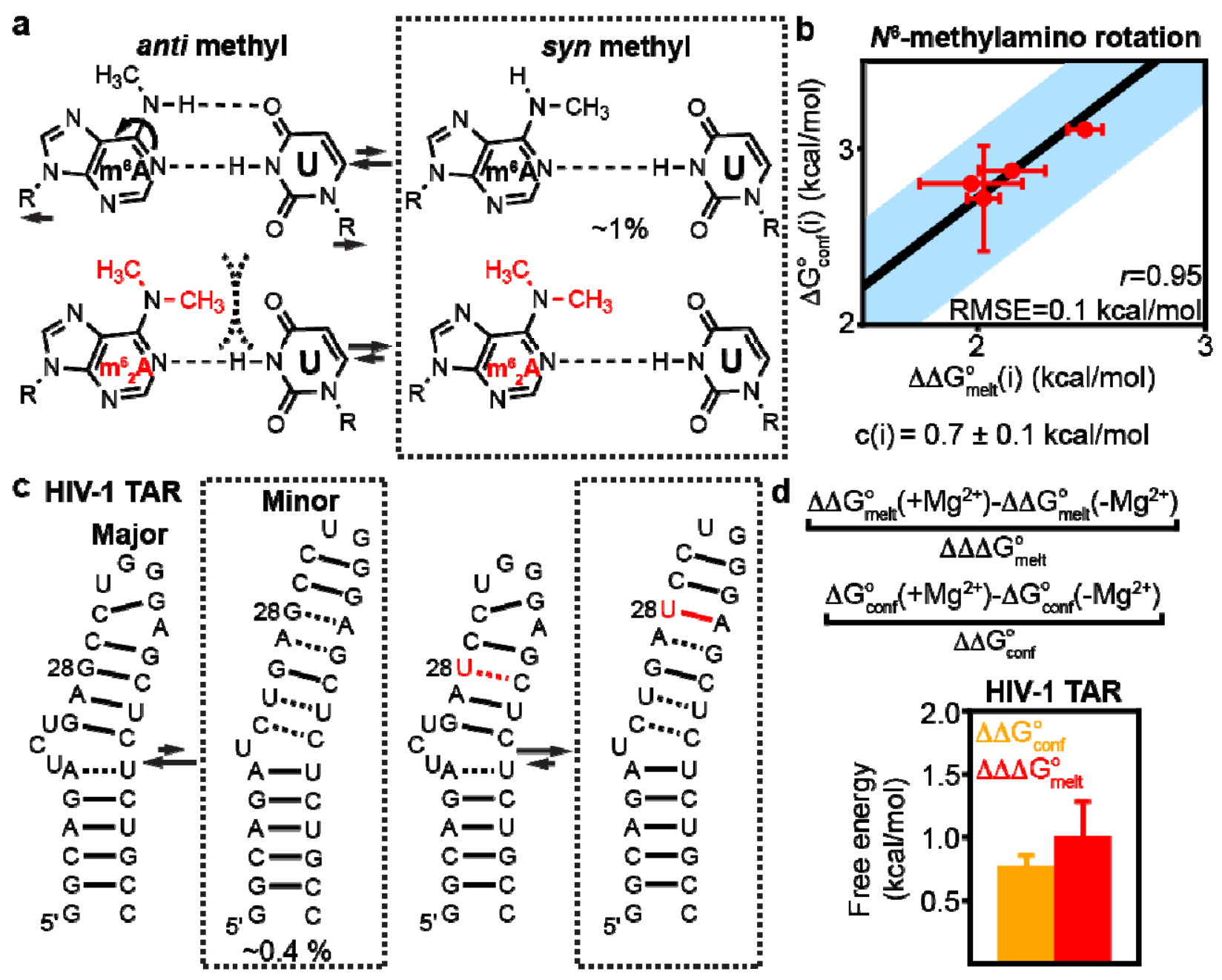

Fig. 3. Applications of delta-Melt to measure conformational penalties in RNA. (a) Dynamic equilibrium between anti and syn conformations of the $N^{6}$-methylamino group of the $\mathrm{m}^{6} \mathrm{~A}-\mathrm{U}$ bp. Biasing the conformational ensemble toward the syn $N^{6}$-methylamino conformation using $m_{2}^{6} \mathrm{~A}$. (b) Correlation $\begin{array}{llll}\text { plot between and for the rotation of the } N^{6} \text {-methylamino group. } & \text { (c) Dynamic }\end{array}$ equilibrium between major and minor conformations of HIV-1 TAR, which can be stabilized by the HIV-1 $\operatorname{TAR}^{\mathrm{G} 28 \mathrm{U}}$ mutant $^{18}$. Solid and dashed lines denote stable bps, and labile bps or mismatches, respectively. (d) Comparison of the difference of $\quad(\quad)$ and $\quad(\quad)$ with and without $1 \mathrm{mM}$ $\mathrm{Mg}^{2+}$. Error bars for NMR and delta-Melt measurements were obtained using a Monte-Carlo scheme and by propagating the uncertainties from UV melts respectively, as described in Methods. Pearson's correlation coefficient $(r)$ and root mean square error (RMSE) were obtained as described in Methods. 
Blue shaded region denotes estimate of error of linear regression obtained using Monte-Carlo simulations as described in Methods.

Finally, we applied delta-Melt to measure the conformational penalties accompanying formation of minor conformations in RNAs ${ }^{19} . N^{6}$-methyl adenine $\left(m^{6} A\right)$ is an abundant epitranscriptomic RNA modification ${ }^{20}$. When paired with uridine, the methylamino group in $\mathrm{m}^{6} \mathrm{~A}$ has recently been shown to isomerize between anti (major) and syn (minor) conformations which results in the loss of a hydrogen-bond ${ }^{21}$ (Fig. 3a). This conformational change has been proposed to play roles slowing a variety of biochemical processes that involve duplex melting and base pairing ${ }^{22}$. It has been shown that $N^{6}, N^{6}$-dimethyl adenosine $\left(\mathrm{m}^{6}{ }_{2} \mathrm{~A}\right)$, when paired with uridine, substantially biases the ensemble toward the minor syn $\mathrm{m}^{6} \mathrm{~A}-\mathrm{U}$ bp conformation ${ }^{21}$. As expected, we observed a good correlation between the differences in the energetics of melting of $\mathrm{m}^{6}{ }_{2} \mathrm{~A}$ relative to $\mathrm{m}^{6} \mathrm{~A}\left(\Delta \Delta \mathrm{G}_{\text {melt }}^{\circ}(\mathrm{i})=\Delta \mathrm{G}_{\text {melt,m6A-U }}^{\circ}-\Delta \mathrm{G}_{\text {melt,m62A-U }}^{\circ}\right)$ and the NMR-derived conformational penalty for $\mathrm{m}^{6} \mathrm{~A}$ isomerization in two different sequence contexts at three different temperatures (Fig. 3b, Supplementary Note 1, Extended Data Figs. 2-4 and 67, and Supplementary Tables 1 and 5-7).

Many unmodified RNAs undergo functionally important transitions to form minor conformations by reshuffling bps in and around non-canonical motifs ${ }^{19}$. Prior studies have shown that point substitution mutations can render these minor conformations the major state ${ }^{19}$. By using such a mutant to substantially bias the conformational ensemble toward a minor conformation in HIV-1 TAR ${ }^{18}$, we used delta-Melt to examine how the conformational penalty to adopt the minor conformation varies with and without 
$1 \mathrm{mM} \mathrm{Mg}^{2+}$. The difference in delta-Melt derived melting energetics with and without $\mathrm{Mg}^{2+}\left(\Delta \Delta \Delta \mathrm{G}_{\text {melt }}^{\circ}=\Delta \Delta \mathrm{G}_{\text {melt }}^{\circ}\left(+\mathrm{Mg}^{2+}\right)-\Delta \Delta \mathrm{G}_{\text {melt }}^{\circ}\left(-\mathrm{Mg}^{2+}\right)\right.$, Extended Data Figs. 2-3 and Supplementary Table 1) were in excellent agreement with those measured independently by NMR RD $\left(\Delta \Delta \mathrm{G}_{\text {conf }}^{\circ}=\Delta \mathrm{G}_{\text {conf }}^{\circ}\left(+\mathrm{Mg}^{2+}\right)-\Delta \mathrm{G}_{\text {conf }}^{\circ}\left(-\mathrm{Mg}^{2+}\right)\right) \quad($ Fig. $3 \mathrm{~d}$, Extended Data Figs. 4 and 6-7, and Supplementary Tables 5-7). These results support the utility of delta-Melt to measure how physiological conditions, post-transcriptional modifications, and mutations alter RNA conformational penalties.

In summary, a broad range of applications indicate that delta-Melt can be used to rapidly and accurately quantify conformational penalties in nucleic acids and to examine how they vary with sequence and physiological conditions. delta-Melt can also be extended to proteins, its throughput can be increased using advanced melting experiments $^{23}$, and it may help guide the discovery of new minor conformations in biomolecules (Supplementary Note 2).

\section{Methods}

\section{Sample preparation}

\section{Buffer preparation}

With the exception of ${ }^{1} \mathrm{H}$ proton exchange measurements (see below), the buffer used in NMR experiments consisted of $15 \mathrm{mM}$ sodium phosphate, 25/125/150 mM sodium chloride and $0.1 \mathrm{mM}$ ethylenediaminetetraacetic acid (EDTA) with or without 1 mM magnesium chloride in $90 \% \mathrm{H}_{2} \mathrm{O}: 10 \% \mathrm{D}_{2} \mathrm{O}$ at pH between 4.4 and 6.8 (summarized in Supplementary Table 5). The buffer used in imino ${ }^{1} \mathrm{H}$ exchange experiments on $\mathrm{G}$ DNA and $A_{6}$-DNA consisted of $10 \mathrm{mM}$ sodium phosphate, $100 \mathrm{mM}$ sodium chloride, 1 
mM EDTA and $1 \mathrm{mM}$ triethanolamine (TEOA) with or without ammonia in $95 \% \mathrm{H}_{2} \mathrm{O}: 5 \%$ $\mathrm{D}_{2} \mathrm{O}$ at $\mathrm{pH}$ 8.8. Buffers with effective ammonia concentrations of $20,40,100$ and 150 $\mathrm{mM}$ were prepared by titrating ammonium hydroxide solution (14.8 M, Millipore Sigma) to the NMR buffer, followed by adjusting $\mathrm{pH}$ to 8.8 by adding hydrochloric acid $(\mathrm{HCl})^{24}$. The effective concentration of ammonia $\left[\mathrm{NH}_{3}\right]$ was computed using the buffer $\mathrm{pH}(8.8)$ and total ammonia concentration added to the buffer $\left(\left[\mathrm{NH}_{3}\right]_{0}\right)$ as follows:

$$
\left[\mathrm{NH}_{3}\right]=\left[\mathrm{NH}_{3}\right]_{0} \frac{10^{-\mathrm{pK}_{\mathrm{a}}^{\mathrm{NH} 3}}}{10^{-\mathrm{pK}_{\mathrm{a}}^{\mathrm{NH} 3}}+10^{-\mathrm{pH}}} \#(1)
$$

where $\mathrm{pK}_{\mathrm{a}}^{\mathrm{NH} 3}$ is the pKa for ammonia. The buffer used in imino ${ }^{1} \mathrm{H}$ exchange experiments on TBP-DNA in the prior study by Chen et al. ${ }^{25}$ consisted of $100 \mathrm{mM}$ sodium chloride, 2 mM EDTA and 2 mM TEOA in $90 \% \mathrm{H}_{2} \mathrm{O}: 10 \% \mathrm{D}_{2} \mathrm{O}$ at $\mathrm{pH} 8.0$.

UV melting experiments for monitoring A-T and G-C+ Hoogsteen bps, methyl rotation in $\mathrm{m}^{6} \mathrm{~A}$, and formation of a minor conformation in HIV-1 TAR were performed in a buffer solution with the same composition as that used for NMR measurements, but in $100 \% \mathrm{H}_{2} \mathrm{O}$. Measurements of UV melting of $\mathrm{A}_{2}$-DNA show that the effect of adding $10 \%$ $\mathrm{D}_{2} \mathrm{O}$ on the melting free energies falls within the error of UV measurements (Supplementary Table 1 and Extended Data Fig. 3). Hence, the lack of $D_{2} \mathrm{O}$ in the buffer used for UV melting is not expected to affect the delta-Melt correlations (Figs. 2d, $f$ and $3 b, d)$. The UV melting experiments for monitoring A-T base opening were performed in buffers with the same $\mathrm{H}_{2} \mathrm{O}: \mathrm{D}_{2} \mathrm{O}$ composition as that for the imino ${ }^{1} \mathrm{H}$ exchange measurements, as defined above. 


\section{Annealing and buffer exchange}

All the duplex DNA and RNA samples were prepared by mixing the two complementary strands in a 1:1 ratio at a concentration of $\sim 1 \mathrm{mM}$, heating to $95{ }^{\circ} \mathrm{C}$ for 5-10 min, followed by slow annealing at room temperature. All the hairpin DNA and RNA samples were prepared by diluting the samples to concentrations $<100 \mu \mathrm{M}$, heating to $95^{\circ} \mathrm{C}$ for $5-10 \mathrm{~min}$, followed by rapid annealing on ice. All the DNA and RNA samples used for NMR measurements were buffer exchanged to desired NMR buffer with final concentration $\sim 1 \mathrm{mM}$ using Amicon Ultra-0.5/15 centrifugal concentrators (3kDa cutoff, Millipore Sigma). The samples used for optical melting experiments were prepared by diluting the NMR samples to $\sim 3 \mu \mathrm{M}$ using buffer. Extinction coefficients for all single strands were estimated using the ADT Bio Oligo Calculator (https://www.atdbio.com/tools/oligo-calculator). Extinction coefficients for the modified single strands were assumed to be equal to their unmodified counterparts (modified bases are estimated to affect the extinction coefficient for the oligos used here by $<10 \%$ based on reference values in Basanta-Sanchez et al. $\left.{ }^{26}\right)$. The DNA-echinomycin complexes were prepared by mixing DNA duplexes in NMR buffer with $3 x$ echinomycin (Sigma-Aldrich) dissolved in methanol, maintaining the NMR buffer:methanol ratio at 2:1 (volume:volume). The mixture was shaken and incubated at room temperature for 30 min, followed by slow solvent evaporation under an air stream overnight. The dried samples were re-dissolved in the appropriate amount of water, ensuring that the final concentration of each buffer component was identical to the NMR buffer. NMR samples 
in $\mathrm{D}_{2} \mathrm{O}$ were prepared by rapidly freezing and lyophilizing samples in water overnight and resuspending them into $100 \% \mathrm{D}_{2} \mathrm{O}$ (Millipore Sigma).

\section{Unlabeled oligonucleotides}

In what follows we use "Ib" inside a bracket following the construct name to refer to specific duplexes (see Extended Data Fig. 4) in which one or both strands are isotopically labeled, and isotopically labeled hairpins. For example, $\mathrm{A}_{6}-\mathrm{DNA}^{\mathrm{m} 1 \mathrm{~A} 16}(\mathrm{~s} 2 \mathrm{lb})$, is a version of the $A_{6}-D_{N A}{ }^{m 1 A 16}$ duplex with a specific labelling scheme defined in Extended Data Fig. 4. Constructs without "lb" in the name are unlabeled. Secondary structures and labeling schemes of all constructs used for NMR measurements are given in Extended Data Fig. 4.

All the unmodified DNA strands were purchased from Integrated DNA Technologies (IDT) with standard desalting purification. The unlabeled $\mathrm{m}^{1} \mathrm{~A}$ modified single strands comprising the $A_{6}-D_{N A}{ }^{m 1 A 16}$ and $A_{6}-D N A^{m 1 A 16}(s 2 l b)$ duplexes were purchased from Midland DNA Technologies with reverse-phase (RP) HPLC purification, while the $m^{1} r G$ modified single strand comprising the $A_{6}$-DNA ${ }^{m 1 r G 10}$ duplex was purchased from GE Healthcare Dharmacon with HPLC purification. Modified single strands comprising constructs $A_{6}-D^{-} A^{m 1 r A 16}, A_{2}-D_{N A}{ }^{m 1 G 6}, A_{2}-D N A^{m 1 G 20}, A_{2}-D N A^{m 1 G 6,20}$, hpAcDNA ${ }^{\mathrm{m} 1 \mathrm{G} 7}, \quad \mathrm{~A}_{2}-\mathrm{DNA} \mathrm{A}^{\mathrm{m} 1 \mathrm{~A} 7}, \quad \mathrm{~A}_{2}-\mathrm{DNA}^{\mathrm{m} 1 \mathrm{~A} 17}, \quad \mathrm{~A}_{2}-\mathrm{DNA}^{\mathrm{m1A7}, 17}, \quad \mathrm{~A}_{2}$-DNA $^{\mathrm{m} 1 \mathrm{~A} 16,17}, \quad \mathrm{~A}_{2}-$

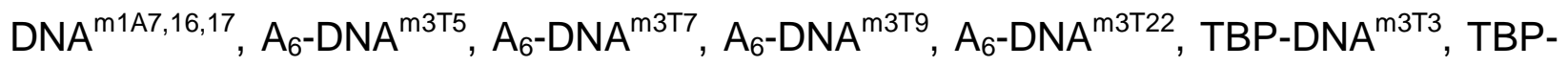

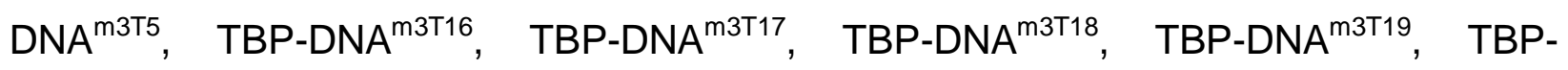
$\mathrm{DNA}^{\mathrm{m} 3 \mathrm{~T} 21}, \mathrm{E} 12 \mathrm{DNA}-\mathrm{HG}^{\mathrm{m} 1 \mathrm{G} 13}$ and E12DNA-HG ${ }^{\text {deazaG13 }}$ were purchased from Yale Keck Oligonucleotide Synthesis Facility with cartridge purification. The $\mathrm{m}^{1} \mathrm{~A}$ modified single 
strand in the $A_{6}-D N A^{m 1 A 21}$ duplex was purchased from Yale Keck Oligonucleotide Synthesis Facility with HPLC purification. The $\mathrm{m}^{1} \mathrm{~A}$ modified single strand comprising the $A_{2}-D N A^{m 1 A 16}$ duplex was purchased from Midland DNA Technologies with RP-HPLC purification and Yale Keck Oligonucleotide Synthesis Facility with cartridge purification for UV melting measurements in pH 6.8 at $25 \mathrm{mM} \mathrm{NaCl}$ and $150 \mathrm{mM} \mathrm{NaCl}$, respectively. The $A_{6}-D N A^{m 1 G 10, m 1 A 16}$ duplex was comprised of an $m^{1} A$ modified single strand purchased from Midland DNA Technologies with RP-HPLC purification, and an $m^{1} G$ modified single strand purchased from Yale Keck Oligonucleotide Synthesis Facility with cartridge purification. To minimize Dimroth rearrangement ${ }^{27}$ of $\mathrm{m}^{1} \mathrm{~A}$ during oligonucleotide synthesis and purification, all the $\mathrm{m}^{1} \mathrm{~A}$ modified DNA single strands were synthesized and deprotected using UltraMild chemistry (https://www.glenresearch.com/reports/gr19-12). The $\mathrm{m}^{1} \mathrm{G} 10$ single strand comprising the $A_{6}-D N A^{m 1 G 10}$ duplex used for UV melting measurements was obtained from Yale Keck Oligonucleotide Synthesis Facility with cartridge purification while that comprising the $A_{6}-D N A^{m 1 G 10}(s 1 l b)$ duplex used for NMR measurements was purchased from Midland DNA Technologies with gel filtration purification.

The $\mathrm{m}^{1} \mathrm{G}$ modified strands in the scaf2 series of DNA duplexes and in $A_{2}$ $D_{N A}{ }^{m 1 G 10}$, the $r A$ modified single strand in $A_{6}-D N A^{r A 16}$ and the unlabeled RNA single strands in $A_{6}-R_{N A}{ }^{m 6 A 16}\left(m^{6} A 16^{\mathrm{C} 2, \mathrm{C} 8} \mathrm{lb}\right), A_{6}-\mathrm{RNA}^{\mathrm{m} 6 \mathrm{~A} 16}, \mathrm{~A}_{6}-\mathrm{RNA}^{\mathrm{m62A16}}$, dsGGACU ${ }^{\mathrm{m} 6 \mathrm{~A} 6}$ and dsGGACU ${ }^{\mathrm{m} 62 \mathrm{~A} 6}$ were synthesized in-house using a MerMade 6 Oligo Synthesizer. Standard RNA phosphoramidites (n-ac-rA, n-ac-rG, n-ac-rC, rU, rm ${ }^{6} A$ and $r m^{6}{ }_{2} A$, Chemgenes) and DNA phosphoramidites (n-ibu-G, n-bz-A, n-ac-C, T and n,n-dmf-m ${ }^{1} \mathrm{G}$, Chemgenes), and columns (1000 A from Bioautomation) were used with a coupling time 
of 6-12 $\min (\mathrm{RNA})$ and $1 \mathrm{~min}(\mathrm{DNA})$, with the final $5^{\prime}$-dimethoxy trityl (DMT) group retained during synthesis. The oligonucleotides were cleaved from the supports (1 umol) using $\sim 1 \mathrm{ml}$ of AMA (1:1 ratio of ammonium hydroxide and methylamine) for 30 min and deprotected at room temperature for 2 hours. The $\mathrm{m}^{1} \mathrm{G}$ containing DNA samples were then purified using Glen-Pak DNA cartridges and ethanol precipitated, while all the other samples were dried under airflow to obtain oligonucleotide crystals. They were then dissolved in $115 \mu \mathrm{LMSO}, 60 \mu \mathrm{l}$ TEA and $75 \mu \mathrm{l}$ TEA.3HF and heated at $65^{\circ} \mathrm{C}$ for $2.5 \mathrm{~h}$ for $2^{\prime}-\mathrm{O}$ deprotection. The samples were then neutralized using $1.75 \mathrm{ml}$ of Glen-Pak RNA quenching buffer, loaded onto Glen-Pak RNA cartridges for purification and were subsequently ethanol precipitated. The rG modified single strand comprising the $A_{6}-D N A^{r G 10}$ duplex used for UV melting measurements was synthesized above as described for the $r A$ modified single strand in $A_{6}$-DNA ${ }^{r A 16}$, while that comprising the $A_{6}-D N A^{r G 10}(s 1 l b)$ duplex used for NMR measurements was purchased from IDT.

TAR and $\operatorname{TAR}^{\mathrm{G} 28 \mathrm{U}}$ were also synthesized in-house using a MerMade 6 Oligo Synthesizer. Standard RNA phosphoramidites (n-ac-rA, n-ac-rG, n-ac-rC, rU, Chemgenes) were used with a coupling time of 6-12 min with the final 5'-DMT group cleaved during synthesis. The oligonucleotides were cleaved from the supports (1 umol) using $\sim 1 \mathrm{ml}$ of AMA for $30 \mathrm{~min}$ and deprotected at room temperature for 2 hours, following which they were air dried to obtain oligonucleotide crystals. The crystals were dissolved in $100 \mu \mathrm{LMSO}$ and $125 \mu \mathrm{TEA} .3 \mathrm{HF}$, and heated at $65^{\circ} \mathrm{C}$ for 2.5 hours for $2^{\prime}-$ O deprotection. The oligonucleotides were then ethanol precipitated and dissolved in $\sim 1 \mathrm{~mL}$ of water, following which $\sim 1 \mathrm{~mL}$ of a formamide based loading dye was added, 
and the mixture was heated at $95 \square^{\circ} \mathrm{C}$ for $5 \square \min$ for denaturation. The mixture was then loaded onto a denaturing gel (20\% 29:1 polyacrylamide/8M urea in Tris-Borate-EDTA (TBE) buffer) for resolution of the target oligonucleotide from other nucleic acid species. Gel bands corresponding to the pure product were identified by UV-shadowing and subject to electroelution (Whatman, GE Healthcare, in Tris-Acetate-EDTA (TAE) buffer) followed by ethanol precipitation.

\section{${ }^{13} \mathrm{C} /{ }^{15} \mathrm{~N}$-labeled oligonucleotides}

The uniformly ${ }^{13} \mathrm{C} /{ }^{15} \mathrm{~N}$ isotope labeled DNA strands comprising duplexes $\mathrm{A}_{6}$ DNA(ulb), $\quad A_{6}-D N A(s 1 l b), \quad A_{6}-D N A(s 2 l b), \quad A_{6}-D N A^{m 1 A 16}(s 2 l b), \quad A_{6}-D N A^{m 1 G 10}(s 1 l b), \quad A_{6}-$ $\mathrm{DNA}^{\mathrm{rG10}}$ (s1lb) and AcDNA(ulb), and residue type (G and T or $\mathrm{C}$ and $\mathrm{A}$ labeled on either strand) DNA strands comprising duplexes $A_{2}$-DNA(ulb) and $A_{2}$-DNA(s2lb) were synthesized using an in vitro primer extension approach ${ }^{28}$ with a template DNA (IDT), Klenow fragment DNA polymerase (New England Biolabs), uniformly ${ }^{13} \mathrm{C},{ }^{15} \mathrm{~N}$-labeled deoxynucleotide triphosphates (dNTPs, Silantes) and/or unlabeled dNTPs (Thermo Fisher Scientific). The reaction mixture was centrifuged to remove excess pyrophosphate, and then subsequently concentrated to $1.5 \square \mathrm{mL}$ using a $3 \square \mathrm{kDa}$ molecular weight cutoff centrifugal concentrator (Millipore Sigma). $1.5 \square \mathrm{mL}$ of a formamide based loading dye was then added to the reaction mixture, which was then heated at $95 \square{ }^{\circ} \mathrm{C}$ for $5 \square \min$ for denaturation. The mixture was then loaded onto a denaturing gel (20\% 29:1 polyacrylamide/8M urea in TBE buffer) for resolution of the target oligonucleotide from other nucleic acid species. Gel bands corresponding to the pure target single strands were identified by UV-shadowing and subject to electroelution 
(Whatman, GE Healthcare, in TAE buffer) followed by ethanol precipitation. Careful optimization of the NTP concentrations, in particular ATP, and that of $\mathrm{Mg}^{2+}$ during primer extension was seen to be necessary to avoid spurious NTP addition to form dangling ends in the resulting oligonucleotides. This was essential to obtain good agreement between the NMR and delta-Melt derived conformational penalties.

The site-specifically labeled DNA strands comprising duplexes $\left(A_{6}-\mathrm{DNA}(\mathrm{A} 16 \mathrm{lb})\right.$, scaf2_CGT ${ }^{G C}(G 6 l b)$ and scaf2_TGC $\left.{ }^{G C}(G 6 l b)\right)$ were purchased from Yale Keck Oligonucleotide Synthesis Facility with cartridge purification.

The atom-specifically labeled DNA and RNA single strands comprising constructs

$$
A_{6}-D N A^{r A 16}\left(r A 16^{\mathrm{C} 8}, \mathrm{C} 15 \mathrm{lb}\right), \quad A_{6}-\mathrm{RNA}^{\mathrm{m} 6 \mathrm{A16}}\left(\mathrm{m}^{6} \mathrm{~A} 16^{\mathrm{C} 2, \mathrm{C} 8} \mathrm{lb}\right),
$$

hpGGACUm ${ }^{6} \mathrm{~A} 6\left(\mathrm{~m}^{6} \mathrm{~A} 6^{\mathrm{C} 2 \mathrm{C} 8 \mathrm{lb}}\right)$ and $\mathrm{hpGGACUm}{ }^{6} \mathrm{~A} 6\left(\mathrm{~m}^{6} \mathrm{~A} 6^{\mathrm{C} 10} \mathrm{lb}\right)$ were synthesized inhouse with a MerMade 6 Oligo Synthesizer as described above for the rA16 modified single strand in $A_{6}-D_{N A}{ }^{r A 16}$, using standard RNA (n-ac-rA, n-ac-rG, n-ac-rC, rU, Chemgenes) and DNA (n-ibu-G, n-bz-A, n-ac-C, T, Chemgenes) phosphoramidites, ${ }^{13} \mathrm{C}$ C8 labeled $\mathrm{rA}^{29},{ }^{13} \mathrm{C} /{ }^{15} \mathrm{~N}$ labeled $\mathrm{C}$ (Cambridge Isotope Laboratories), ${ }^{13} \mathrm{C} \mathrm{C} 2$ and $\mathrm{C} 8$ labeled $r \mathrm{rm}^{6} \mathrm{~A}^{22},{ }^{13} \mathrm{C} \mathrm{C} 2$ and $\mathrm{C} 8$ labeled $\mathrm{rA}^{30},{ }^{15} \mathrm{~N}$ N3 labeled $\mathrm{rU}^{31}$ and ${ }^{13} \mathrm{C} \mathrm{C} 10$ labeled $\mathrm{rm}^{6} \mathrm{~A}$ phosphoramidites ${ }^{21}$. $\operatorname{TAR}\left(\mathrm{U} 23^{\mathrm{C} 6}, \mathrm{G} 34^{\mathrm{C} 8}, \mathrm{U} 38^{\mathrm{N} 3} \mathrm{lb}\right)$ was synthesized using the Mermade Oligo Synthesizer as described above for the TAR and TAR ${ }^{\mathrm{G} 28 \mathrm{U}}$ samples, while using standard RNA (n-ac-rA, n-ac-rG, n-ac-rC, rU, Chemgenes), ${ }^{13} \mathrm{C}$ C6 labeled $\mathrm{rU}^{32},{ }^{13} \mathrm{C} \mathrm{C} 8$ labeled $\mathrm{rG}^{29}$ and ${ }^{15} \mathrm{~N}$ N3 labeled $\mathrm{rU}^{31}$ phosphoramidites.

\section{NMR experiments}


The imino ${ }^{1} \mathrm{H}$ exchange experiments were carried out on a Bruker Avance III 700 $\mathrm{MHz}$ spectrometer equipped with a $\mathrm{HCN}$ room temperature probe while the remaining NMR data was collected on Bruker Avance III $600 \mathrm{MHz}$ or $700 \mathrm{MHz} \mathrm{NMR}$ spectrometers equipped with HCPN and HCN cryogenic probes, respectively.

\section{$\underline{\text { Resonance assignment }}$}

Resonance assignments for $A_{6}-D N A, A_{6}-D N A^{m 1 A 16}, A_{6}-D N A^{m 1 G 10}, A_{6}-D N A^{r A 16}, A_{6}-$ $\mathrm{DNA}^{\mathrm{rG10}}, \mathrm{A}_{2}$-DNA, AcDNA, hpGGACU ${ }^{\mathrm{m} 6 \mathrm{A6}}$, G-DNA, TAR, E12DNA-HG and E12DNAWC were obtained from prior studies ${ }^{9,14,33-36}$ (Extended Data Fig. 4). Assignments for $A_{6}-R_{N A}{ }^{m 616}$ will be published in a subsequent study ${ }^{21}$. Note that the $\mathrm{C} 1^{\prime}-\mathrm{H} 1^{\prime}$ assignments for T5 and T6 were incorrectly swapped in assignments of $A_{6}-D N A, A_{6}{ }^{-}$ $D_{N A}{ }^{m 1 A 16}, A_{6}-D N A^{m 1 G 10}, A_{6}-D N A^{r A 16}, A_{6}-D N A^{m 1 r A 16}, A_{6}-D N A^{r G 10}, A_{6}-D N A^{m 1 r G 10}$ in prior studies $^{9,13,14,37-39}$. Nevertheless, the conclusions of these prior studies are not affected by the assignment swap. The assignment swap has been corrected in the assignments in this study and in the BMRB entries 30254 and $30255 . \quad$ Resonance assignments for $A_{6}-D N A^{\text {m3T9 }}$ were obtained using 2D $\left[{ }^{1} \mathrm{H},{ }^{1} \mathrm{H}\right]$ Nuclear Overhauser Effect Spectroscopy (NOESY), 2D $\left[{ }^{1} \mathrm{H},{ }^{1} \mathrm{H}\right]$ Total Correlation Spectroscopy (TOCSY) and $2 \mathrm{D}\left[{ }^{13} \mathrm{C},{ }^{1} \mathrm{H}\right]$ Heteronuclear Single Quantum Correlation (HSQC) experiments. The assignments for scaf2_CGT ${ }^{\mathrm{GC}}$ and scaf2_TGC ${ }^{\mathrm{GC}}$ were easily obtained since they were site-specifically labeled. All the NMR spectra were processed using NMRpipe ${ }^{40}$ and analyzed using SPARKY (T. D. Goddard and D. G. Kneller, SPARKY 3, University of California, San Francisco). 
${ }^{13} \mathrm{C} /{ }^{15} \mathrm{~N} R_{1 \rho}$ relaxation dispersion

Off-resonance ${ }^{13} \mathrm{C} /{ }^{15} \mathrm{~N} \quad R_{1 \rho}$ relaxation dispersion (RD) experiments were implemented using a 1D selective excitation scheme as described in prior studies ${ }^{38,41,}$ 42. The spin-lock power $\left(\omega_{1} / 2 \pi\right)$ used ranged from 100 to $1000 \mathrm{~Hz}$, while the offsets used ranged from \pm 10 and \pm 3.5 times the spin-lock power for ${ }^{13} \mathrm{C}$ and ${ }^{15} \mathrm{~N}$ experiments, respectively (Supplementary Table 6). For each resonance, six to ten delay times were selected during the relaxation period with maximum duration up to $60 \mathrm{~ms}$ and $150 \mathrm{~ms}$ for ${ }^{13} \mathrm{C}$ and ${ }^{15} \mathrm{~N}$, respectively. The experimental conditions for all the ${ }^{13} \mathrm{C} /{ }^{15} \mathrm{~N} R_{1 \rho} \mathrm{RD}$ experiments (temperature, magnetic field, solvent) are summarized in Supplementary Table 5.

\section{$\underline{\text { Analysis of } R_{1 \underline{p}} \text { data }}$}

The $R_{1 \rho}$ data was analyzed as described previously ${ }^{43}$. Briefly, 1D peak intensities as a function of delay times extracted using NMRPipe ${ }^{40}$ were fitted to a mono-exponential decay to obtain the $R_{1 \rho}$ value for the different spin-lock power and offset combinations. The error in $R_{1 \rho}$ was estimated using a Monte Carlo procedure as described previously ${ }^{19}$. Exchange parameters of interests, such as the population of the $\mathrm{i}^{\text {th }}$ minor conformation $\left(p_{\mathrm{i}}\right)$, the exchange rate between the major and $\mathrm{i}^{\text {th }}$ minor conformation $\left(k_{\mathrm{ex}}=k_{1}+k_{-1}\right.$, in which $k_{1}$ and $k_{-1}$ are the forward and backward rate constants, respectively), the chemical shift difference between the $i^{\text {th }}$ minor and the major conformations $\left(\Delta \omega_{i-M a j o r}=\omega_{i}-\omega_{\text {Major }}\right.$ in which $\omega_{i}$ and $\omega_{\text {Major }}$ are the chemical shifts of the nucleus in the $\mathrm{i}^{\text {th }}$ minor and the major conformations, respectively) were then extracted by fitting the $R_{1 p}$ data for a given nucleus to a two-state exchange model using 
the Bloch-McConnell equations. Owing to the presence of an equilibration delay (5 ms) in the pulse sequence ${ }^{38,41}$, initial magnetization at the start of the Bloch-McConnell simulations was assumed to be equilibrated between the major and minor conformations. Combined fits of the $R_{1 p}$ data for multiple nuclei were performed by sharing $p_{\mathrm{i}}$ and $k_{\mathrm{ex}}$. Owing to the weak nature of the RD profiles (see below) for G6-C1' and $\mathrm{C} 8$ in scaf2_TGC ${ }^{\mathrm{GC}}$ at $\mathrm{pH} 5.4150 \mathrm{mM} \mathrm{NaCl}$ (high salt, $>25 \mathrm{mM}, \mathrm{HS}$ ) and $40^{\circ} \mathrm{C}$, the values of $\Delta \omega_{\mathrm{i}-\text { Major }}$ obtained when fitting both data sets with shared $p_{\mathrm{i}}$ and $k_{\mathrm{ex}}$ were seen to deviate significantly from values determined under low salt $\left(25 \mathrm{mM}, 30{ }^{\circ} \mathrm{C}\right)$ conditions, where RD profiles were stronger and more well defined (Extended Data Fig. 6). Thus, the high salt data set at $40^{\circ} \mathrm{C}$ was fit while fixing $\Delta \omega_{\mathrm{i}-\text { Major }}$ for $\mathrm{G} 6-\mathrm{C} 1^{\prime}$ and $\mathrm{G} 6$ $\mathrm{C} 8$ to the values obtained from RD measurements under low salt $\left(25 \mathrm{mM}, 30{ }^{\circ} \mathrm{C}\right)$ conditions (Supplementary Table 7).

It should be noted that in addition to sensing conformational changes at the bp (active exchange), RD measurements at a given nucleus can also have contributions from conformational changes at neighboring bases (passive exchange) that need to be accounted for during fitting of the data ${ }^{13,43,44}$. Such passive contributions are expected to be small $\left(R_{\mathrm{ex}} \sim<1 \mathrm{~s}^{-1}\right)$ and not affect the extracted exchange parameters for most of the RD profiles measured in this study as they are strong (fitted $R_{\mathrm{ex}}$ values of $>\sim 4 \mathrm{~s}^{-1}$ ), and given the small magnitude of the passive chemical shift changes $\left(\Delta \omega_{i-M a j o r}<\sim 0.5\right.$ ppm). Nevertheless, nuclei for which the RD profiles are intrinsically weak, with fitted $R_{\mathrm{ex}}$ values of $<\sim 4 \mathrm{~s}^{-1}$ (G10-C1' in $\mathrm{A}_{6}$-DNA at pH $6.825^{\circ} \mathrm{C}, \mathrm{A} 16-\mathrm{C} 8$ in $\mathrm{A}_{2}$-DNA at pH 6.8 $25^{\circ} \mathrm{C}$, and $\mathrm{G} 6-\mathrm{C} 11^{\prime}$ and $\mathrm{G} 6-\mathrm{C} 8$ in scaf2_TGC ${ }^{\mathrm{GC}}$ at $\mathrm{pH} 5.4 \mathrm{HS} 30^{\circ} \mathrm{C}$ and $40{ }^{\circ} \mathrm{C}$ ) are likely 
to be influenced to a greater extent by such passive exchange contributions relative to nuclei with stronger RD profiles. These passive contributions could also cause deviations from the true exchange parameters for the active exchange when fitting the data assuming a two-state model. However, given the weak nature of the RD profiles, it is difficult to robustly fit them to a three-state exchange model to extract exchange parameters for both the active and passive exchange. Thus, we have fit these weak RD profiles (G10-C1' in $A_{6}$-DNA at pH $6.825^{\circ} \mathrm{C}, \mathrm{A} 16-\mathrm{C} 8$ in $\mathrm{A}_{2}$-DNA at pH $6.825^{\circ} \mathrm{C}$, and G6-C1' and G6-C8 in scaf2_TGC ${ }^{\mathrm{GC}}$ at $\mathrm{pH} 5.4 \mathrm{HS} 30{ }^{\circ} \mathrm{C}$ and $40{ }^{\circ} \mathrm{C}$ ) assuming a twostate exchange model and suggest that the fitted exchange parameters be interpreted with caution, and have highlighted these weak data sets using open symbols and * in Figs. $2 d$, f and $g$.

The uncertainty in the exchange parameters was obtained using a Monte-Carlo scheme as described previously ${ }^{45}$. All the fitting parameters have been summarized in Supplementary Table 7 . The sensitivity of the fit to the $R_{1 p}$ data to changes in $p_{i}$ was examined by computing the reduced $\chi^{2}$ while fixing $p_{i}$ to a range of different values (Extended Data Fig. 7). Off-resonance $R_{1 p}$ profiles (Fig. 2g, Extended Data Fig. 6) were generated by plotting $\left(R_{2}+R_{\mathrm{ex}}\right)=\left(R_{1 \rho}-R_{1} \cos ^{2} \theta\right) / \sin ^{2} \theta$, where $\theta$ is the angle between the effective field of the observed resonance and the z-axis, as a function of $\Omega_{\mathrm{OBS}}=$ $\omega_{\mathrm{OBS}}-\omega_{\mathrm{RF}}$, in which $\omega_{\mathrm{OBS}}$ is the Larmor frequency of the observed resonance and $\omega_{\mathrm{RF}}$ is the angular frequency of the applied spin-lock. Errors in $\left(R_{2}+R_{\mathrm{ex}}\right)$ were determined by propagating the error in $R_{1 p}$ obtained as described above.

Alignment of initial magnetization during the Bloch-McConnell fitting was performed based on the $k_{\mathrm{ex}} / \Delta \omega_{\mathrm{i}-\text { Major }}$ ratio as described previously ${ }^{19}$. Interestingly, RD 
profiles for $\mathrm{A} 21-\mathrm{C} 11^{\prime}$ in $\mathrm{A}_{6}-\mathrm{DNA}$ at $25^{\circ} \mathrm{C}$ and $30{ }^{\circ} \mathrm{C}, \mathrm{G} 10-\mathrm{C} 11^{\prime}$ in $\mathrm{A}_{6}-\mathrm{DNA}$ at $\mathrm{pH} 6.825^{\circ} \mathrm{C}$, and G6-C1' and $\mathrm{C} 8$ in scaf2_TGC ${ }^{\mathrm{GC}} \mathrm{pH} 5.4 \mathrm{HS} 30^{\circ} \mathrm{C}$ and $40^{\circ} \mathrm{C}$ could be better fit with a highly populated ES on the order of a few percent in slow exchange, while assuming alignment along the ground state effective field. Nevertheless, these highly populated solutions were excluded based on the lower populations measured previously for a wide range of sequence contexts in DNA (in the case of $A 21-C 1$ ' in $A_{6}$-DNA at 25 and 30 ${ }^{\circ} \mathrm{C}$ ) ${ }^{46}$, and alternative measurements at $\mathrm{pH} 5.4$ (in the case of $\mathrm{G} 10-\mathrm{C} 1$ ' in $\mathrm{A}_{6}$-DNA at pH $6.825^{\circ} \mathrm{C}$ ) and at low salt (G6-C1' and C8 in scaf2_TGC ${ }^{\mathrm{GC}} \mathrm{pH} 5.430$ and $40{ }^{\circ} \mathrm{C}$ ) wherein the exchange parameters were seen to be robust. Thus, the alignment of magnetization for $\mathrm{A} 21-\mathrm{C} 11^{\prime}$ in $\mathrm{A}_{6}$-DNA at 25 and $30^{\circ} \mathrm{C}, \mathrm{G} 6-\mathrm{C} 11^{\prime}$ and $\mathrm{C} 8$ in scaf2_TGC $\mathrm{GC}$ $\mathrm{pH} 5.4 \mathrm{HS} 30^{\circ} \mathrm{C}$ and $40^{\circ} \mathrm{C}$ was fixed to be along the effective field of the population averaged state when plotting the reduced $\chi^{2}$ profiles as a function of $p_{\mathrm{i}}$ (Extended Data Fig. 7).

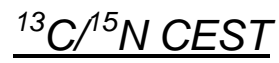

${ }^{13} \mathrm{C} /{ }^{15} \mathrm{~N}$ CEST experiments on the aromatic $\mathrm{C} 6 / \mathrm{C} 8 / \mathrm{C} 2$ and $\mathrm{C} 1$ ' carbons, and imino nitrogen U-N3 atoms were carried out using a pulse sequence employing a selective excitation scheme in a 1D manner, as described previously ${ }^{22,47,48}$. The ${ }^{13} \mathrm{C}$ CEST experiments on the methyl carbon in hpGGACU ${ }^{\mathrm{m} 6 \mathrm{~A}}\left(\mathrm{~m}^{6} \mathrm{~A} 6^{\mathrm{C10}} \mathrm{lb}\right)$ were carried out in a $2 \mathrm{D}$ mode using a pulse sequence derived from prior ${ }^{13} \mathrm{C}$ CEST pulse sequences ${ }^{21}$, 47,49 .

For ${ }^{13} \mathrm{C}$ and ${ }^{15} \mathrm{~N}$ CEST, the spin-lock power ranged from 10 to $70 \mathrm{~Hz}$ and from 10 to $50 \mathrm{~Hz}$, respectively. The list of spin-lock power offset combinations used for CEST 
experiments can be found in Supplementary Table 6. A relaxation time of $200 \mathrm{~ms}$ was used for all CEST experiments apart from U38-N3 in TAR in the absence of $\mathrm{Mg}^{2+}$, for which $300 \mathrm{~ms}$ was used. The experimental conditions for all the ${ }^{13} \mathrm{C} /{ }^{15} \mathrm{~N}$ CEST experiments (temperature, magnetic field, solvent) have been summarized in Supplementary Table 5.

\section{Analysis of CEST data}

The analysis of CEST data was performed as described previously ${ }^{22,48}$. Briefly, 1D peak intensities were obtained in a manner similar to that for $R_{1 p}$. All intensities at a given radio-frequency $(\mathrm{RF})$ power were normalized by the average of the intensities over the triplicate CEST measurements with zero relaxation delay using the same RF power, to obtain normalized CEST profiles. Normalized CEST profiles were plotted as a function of offset $\Omega=\omega_{\mathrm{RF}}-\omega_{\mathrm{OBS}}$, in which $\omega_{\mathrm{OBS}}$ is the Larmor frequency of the observed resonance and $\omega_{\mathrm{RF}}$ is the angular frequency of the applied spin-lock (Extended Data Fig. 6). The error in the intensity for each RF power was obtained as the standard deviation of triplicate experiments with zero relaxation delay and same RF power. Exchange parameters of interest $\left(p_{\mathrm{i}}, k_{\mathrm{ex}}, \Delta \omega_{\mathrm{i}-\text { Major }}\right)$ were then extracted by fitting the normalized CEST profiles to a two-state exchange model using the Bloch-McConnell equations. Combined fits of the CEST data for multiple nuclei were performed by sharing $p_{\mathrm{i}}$ and $k_{\mathrm{ex}}$.

Treatment of spin-lock inhomogeneity and alignment of the initial magnetization during CEST fitting was performed as described previously ${ }^{48}$. Only GS magnetization was considered to be present at the start of the relaxation delay during CEST fitting for 
the $\mathrm{C} 2 / \mathrm{C} 6 / \mathrm{C} 8 / \mathrm{C} 1$ ' and imino nitrogen spins, owing to the absence of the equilibration delay in the pulse sequence. GS and ES magnetization was considered to be equilibrated while fitting the methyl CEST data on hpGGACU ${ }^{\mathrm{m} 6 \mathrm{A6}}\left(\mathrm{m}^{6} \mathrm{~A} 6^{\mathrm{C} 10} \mathrm{lb}\right)$ as the pulse sequence employs hard pulses to excite spins ${ }^{21}$. The sensitivity of the fit to the CEST data to changes in $p_{\mathrm{i}}$ was examined by computing the reduced $\chi^{2}$ while fixing $p_{\mathrm{i}}$ to a range of different values (Extended Data Fig. 7). All the fitting parameters from CEST experiments have been summarized in Supplementary Table 7. The errors of all the fitting parameters were estimated using 100 Monte Carlo iterations as described previously $^{22}$.

\section{$\underline{\text { Imino }}{ }^{1} \mathrm{H}$ exchange}

The kinetics of base opening were determined using a combination of experiments including a saturation recovery experiment to measure water proton $R_{1}$ $\left(R_{1 \mathrm{w}}\right)$ and a magnetization transfer experiment to measure the exchange rate of the imino proton with water, as described previously ${ }^{24}$. The relaxation delay times for measuring water proton $R_{1}$ were $0.0,0.4,0.8,1.2,1.6,2.0,2.4,2.8,3.2,3.6,4.0,4.4$, $4.8,5.2,6.0,7.0,8.0,9.0,10.0,12.0$ and $15.0 \mathrm{sec}$. The series of relaxation delay times for all the imino ${ }^{1} \mathrm{H}$ exchange measurements in this study are listed in Supplementary Table 2.

\section{Analysis of imino ${ }^{1} \mathrm{H}$ exchange data}


The net exchange rate $\left(k_{\mathrm{ex}}\right)$ between imino and water proton can be measured by fitting the $1 \mathrm{D}$ imino ${ }^{1} \mathrm{H}$ peak volume at each delay time $(\mathrm{t})$ in the magnetization transfer experiment to Equation 2 shown below,

$$
\begin{gathered}
\frac{\mathrm{W}(\mathrm{t})}{\mathrm{W}_{0}}=1-\mathrm{E} \times \frac{k_{\mathrm{ex}}}{R_{1 \mathrm{w}}-R_{1 \mathrm{n}}} \times\left(e^{-R_{1 \mathrm{n}} \mathrm{t}}-e^{-R_{1 \mathrm{w}} \mathrm{t}}\right) \#(2) \\
R_{1 \mathrm{n}}=R_{1}+k_{\mathrm{ex}} \#(3)
\end{gathered}
$$

where $\mathrm{W}(\mathrm{t})$ is the imino ${ }^{1} \mathrm{H}$ peak volume as a function of relaxation delay time $t, \mathrm{~W}^{0}$ is the initial imino ${ }^{1} \mathrm{H}$ peak volume at zero delay, $\mathrm{W}(\mathrm{t}) / \mathrm{W}^{0}$ is the normalized peak volume, $\mathrm{E}$ is the efficiency of the pulse for inverting water, $R_{1 \mathrm{n}}$ represents the summation of imino ${ }^{1} \mathrm{H} R_{1}$ and $k_{\text {ex }}$. In the above equation, $R_{1 \mathrm{w}}$ and $\mathrm{E}$ are fixed parameters while $k_{\mathrm{ex}}$ and $R_{1}$ are fitting parameters. The error of all the fitting parameters was set to be equal to the standard fitting error, obtained as the square root of the diagonal elements of the covariance matrix of the fitting parameters. We also examined the sensitivity of the fitting to changes in the fitting parameter $k_{\text {ex }}$ by fixing $k_{\text {ex }}$ to a range of values and plotting the residual sum of squares (RSS) as a function of $k_{\text {ex }}$ (Extended Data Fig. 5). All the fitting parameters have been summarized in Supplementary Table 4 . The efficiency of the inversion pulse was computed as follows,

$$
\mathrm{E}=1-\frac{\mathrm{W}_{\mathrm{inv}}}{\mathrm{W}_{\mathrm{eq}}} \#(4)
$$


where $W_{\text {inv }}$ and $W_{\text {eq }}$ are the peak volumes of the water proton with and without applying the inversion pulse in the magnetization exchange experiment (with zero relaxation delay and no water suppression), respectively.

To obtain the population $p_{\mathrm{i}}$ of the base opened state, the net $k_{\mathrm{ex}}$ between imino proton and water was measured in the presence of different effective ammonia concentrations ( $20 \mathrm{mM}, 40 \mathrm{mM}, 100 \mathrm{mM}$ and $150 \mathrm{mM})$, and the inverse of $k_{\mathrm{ex}}\left(\tau_{e x}=1 / k_{\mathrm{ex}}\right)$ was linearly fit to the inverse of the effective ammonia concentration using Equation 5,

$$
\tau_{e x}=\frac{1}{k_{\mathrm{ex}}}=\tau_{0}+\frac{\frac{1}{\alpha K_{\mathrm{diss}}}}{k_{\mathrm{B}}\left[\mathrm{NH}_{3}\right]} \#(5)
$$

where $\tau_{0}$ is the inverse of the base opening rate (lifetime of the closed state), $\alpha$ is the base catalyst accessibility factor which is generally assumed to be $1^{50},\left[\mathrm{NH}_{3}\right]$ is the effective ammonia concentration, $K_{\text {diss }}$ is the bp dissociation constant defined by,

$$
K_{\text {diss }}=\frac{p_{\mathrm{i}}}{1-p_{\mathrm{i}}} \#(6)
$$

and $k_{\mathrm{B}}$ is the rate constant for exchange catalysis which is given by,

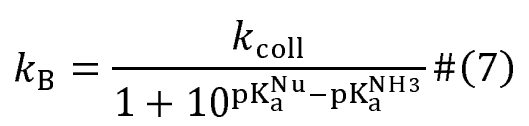


where $k_{\text {coll }}$ is the bi-molecular collision rate constant between the imino proton and ammonia in the open state, and $\mathrm{pK}_{\mathrm{a}}^{\mathrm{Nu}}$ and $\mathrm{pK}_{\mathrm{a}}^{\mathrm{NH} 3}$ are the pKa for the imino proton in the open state and ammonia, respectively. Under the conditions used in our study $k_{\mathrm{B}}$ is equal to $2.5 \times 10^{8} \mathrm{M}^{-1} \mathrm{~s}^{-1}$ at $25^{\circ} \mathrm{C}^{50}$.

Given the errors obtained for $k_{\mathrm{ex}}$ based on the covariance matrix as described above, Monte-Carlo simulations were performed to compute the errors in $K_{\text {diss. }}$ In particular, $1 / k_{\text {ex }}$ at each ammonia concentration was sampled from a gaussian with mean equal to the average fit $1 / k_{\mathrm{ex}}$ value and standard deviation equal to the error in $1 / k_{\text {ex. }}$ The sampling was repeated for all ammonia concentrations for a given iteration, and the variation of $1 / k_{\text {ex }}$ vs. $1 /\left[\mathrm{NH}_{3}\right]$ was fit to compute a $K_{\text {diss }}$ value. The procedure was repeated for 10,000 iterations and the mean and standard deviation of the resultant $K_{\text {diss }}$ distribution were set to be equal to the mean and error of the fitted $K_{\text {diss. }}$ The region spanned by the family of straight lines thus obtained is colored blue in Extended Data Fig. 5. The error in $p_{\mathrm{i}}$ was determined by propagating the error in $K_{\text {diss }}$ (Supplementary Table 4).

To benchmark our implementation of the imino ${ }^{1} \mathrm{H}$ exchange measurements in this study, we compared our measurements on T6 in G-DNA at $25^{\circ} \mathrm{C}$ to a prior study ${ }^{50}$ and obtained a consistent conformational penalty for opening (Extended Data Fig. 5). $p_{i}$ values for T3, T5, T16, T17, T18, T19 and T21 in TBP-DNA at $15^{\circ} \mathrm{C}$ were obtained from a prior study ${ }^{25}$.

\section{Optical melting}

\section{Experiments and sample conditions}


Optical melting experiments were carried out on a PerkinElmer Lambda 25 UV/VIS spectrometer with a RTP 6 Peltier Temperature Programmer and a PCB 1500 Water Peltier System. At least three measurements were carried out for each DNA and RNA duplex using a sample volume of $400 \mu \mathrm{L}$ in a Teflon-stoppered $1 \mathrm{~cm}$ path length quartz cell. The absorbance at $260 \mathrm{~nm}$ was monitored while the temperature was varied at a ramp rate of $1^{\circ} \mathrm{C} / \mathrm{min}$.

\section{$\underline{\text { Data analysis }}$}

The melting temperature $\left(T_{m}\right)$ and standard enthalpy change of melting $\left(\Delta \mathrm{H}_{\text {melt,WT }}\right.$ or $\left.\Delta \mathrm{H}_{\text {melt,Mut }}\right)$ (Fig. $\left.1 \mathrm{~d}\right)$, respectively, were obtained by fitting the absorbance at $260 \mathrm{~nm}\left(\mathrm{~A}_{260}\right)$ from the optical melting experiment to Equation 8,

$$
\mathrm{A}_{260}=\left(\left(\left(m_{\text {melt }} * \mathrm{~T}\right)+b_{\text {melt }}\right) * p_{\text {melt }}\right)+\left(\left(\left(m_{\text {fold }} * \mathrm{~T}\right)+b_{\text {fold }}\right) \times\left(1-p_{\text {melt }}\right)\right) \#(8)
$$

where $m_{\text {melt }}, b_{\text {melt }}, m_{\text {fold }}$ and $b_{\text {fold }}$ are coefficients describing the temperature dependence of the extinction coefficients for the melted and folded species, respectively, and $p_{\text {melt }}$ is the population of the melted duplex/hairpin species. $p_{\text {melt }}$ for a WT duplex and hairpin are given by the following expressions (analogous expressions can also be written for melting of Mut by replacing WT by Mut),

$$
p_{\text {melt }}=1-\frac{1+4 \mathrm{e}^{-\left(\frac{1}{\mathrm{~T}_{\mathrm{m}}}-\frac{1}{\mathrm{~T}}\right) \frac{\Delta \mathrm{H}_{\text {melt,WT }}}{\mathrm{R}}}-\sqrt{1+8 \mathrm{e}^{-\left(\frac{1}{\mathrm{~T}_{\mathrm{m}}}-\frac{1}{\mathrm{~T}}\right) \frac{\Delta \mathrm{H}_{\mathrm{melt}, \mathrm{WT}}}{\mathrm{R}}}}}{4 \mathrm{e}^{-\left(\frac{1}{\mathrm{~T}_{\mathrm{m}}}-\frac{1}{\mathrm{~T}}\right) \frac{\Delta \mathrm{H}_{\text {melt }, \mathrm{WT}}}{\mathrm{R}}}} \#(9)
$$


and

$$
p_{\text {melt }}=1-\frac{\mathrm{e}^{-\left(\frac{1}{\mathrm{~T}_{\mathrm{m}}}-\frac{1}{\mathrm{~T}}\right) \frac{\Delta \mathrm{H}_{\text {melt }, \mathrm{WT}}}{\mathrm{R}}}}{1+\mathrm{e}^{-\left(\frac{1}{\mathrm{~T}_{\mathrm{m}}}-\frac{1}{\mathrm{~T}}\right) \frac{\Delta \mathrm{H}_{\mathrm{melt}, \mathrm{WT}}}{\mathrm{R}}}} \#(10)
$$

respectively, where $T_{m}$ is the melting temperature $(K), T$ is the temperature $(K)$, and $R$ is the gas constant $(\mathrm{kcal} / \mathrm{mol} / \mathrm{K})$.

The standard entropy change $\left(\Delta \mathrm{S}_{\text {melt,WT }}\right.$ or $\left.\Delta \mathrm{S}_{\text {melt,Mut }}\right)$ and free energy change $\left(\Delta \mathrm{G}_{\text {melt,WT }}\right.$ or $\left.\Delta \mathrm{G}_{\text {melt,Mut }}\right)$ of melting were computed using Equations 11 and 12 for a duplex and hairpin, respectively,

$$
\begin{gathered}
\Delta \mathrm{S}_{\text {melt }, \mathrm{WT}}=\frac{\Delta \mathrm{H}_{\mathrm{melt}, \mathrm{WT}}}{\mathrm{T}_{\mathrm{m}}}+\mathrm{R} \ln \left(\frac{\mathrm{C}_{\mathrm{T}}}{2}\right) \#(11) \\
\Delta \mathrm{S}_{\mathrm{melt}, \mathrm{WT}}=\frac{\Delta \mathrm{H}_{\mathrm{melt}, \mathrm{WT}}}{\mathrm{T}_{\mathrm{m}}} \#(12)
\end{gathered}
$$

where $\mathrm{C}_{\mathrm{T}}$ is total concentration of the duplex/hairpin. Using the obtained enthalpies and entropies, the free energy of melting was then computed as follows,

$$
\Delta \mathrm{G}_{\text {melt }, \mathrm{WT}}=\Delta \mathrm{H}_{\text {melt,WT }}-\mathrm{T} \Delta \mathrm{S}_{\text {melt,WT}} \#(13)
$$


The mean values and uncertainties in $\mathrm{T}_{\mathrm{m}}, \Delta \mathrm{H}_{\text {melt,WT }}, \Delta \mathrm{S}_{\text {melt,WT }}$ and $\Delta \mathrm{G}_{\text {melt,WT }}$ were set to be equal to the average and standard deviation from multiple measurements $(n>=3)$.

For UV melting profiles of TAR with $1 \mathrm{mM} \mathrm{Mg}^{2+}, \mathrm{TAR}^{\mathrm{G} 28 \mathrm{U}}$ with and without $1 \mathrm{mM}$ $\mathrm{Mg}^{2+}$, scaf2_AGG ${ }^{\mathrm{m} 1 \mathrm{GC}}$ and scaf2_TGG ${ }^{\mathrm{m} 1 \mathrm{GC}}$ (Extended Data Fig. 2), minor deviations from two-state fits were observed in the lower baseline which could potentially arise from the existence of multiple folded species in equilibrium with each other ${ }^{51}$. Due to the lack of knowledge about the second folded species for the above samples, we have chosen to fit the UV curves for them assuming a two-state model. Melting data with similar minor deviations has also been fit assuming a two-state approximation to extract thermodynamics parameters in the literature ${ }^{52}$. Nevertheless, understanding the conformational dynamics that gives rise to such minor deviations and how that affects the interpretation of the melting data will be the subject of future studies.

\section{Comparison of conformational penalties between NMR experiments and delta-}

\section{Melt}

For a given equilibrium between the major and $i^{\text {th }}$ minor conformation, Major $\Leftrightarrow$ Minor, the conformational penalty $\left(\Delta \mathrm{G}_{\text {conf }}(\mathrm{i})\right)$ measured by $\mathrm{NMR}$ experiments was computed as follows,

$$
\Delta \mathrm{G}_{\text {conf }}(\mathrm{i})=-\mathrm{RT} \ln \left(\frac{p_{\mathrm{i}}}{1-p_{\mathrm{i}}}\right) \#(14)
$$


where $T$ is the temperature $(K), R$ is the gas constant $(\mathrm{kcal} / \mathrm{mol})$ and $p_{i}$ is the population of the $\mathrm{i}^{\text {th }}$ minor conformation, respectively. Errors in $\Delta \mathrm{G}_{\text {conf }}(\mathrm{i})$ were obtained by propagating the error in $p_{i}$ obtained from the NMR measurements.

The enthalpy $\left(\Delta \mathrm{H}_{\text {conf }}(\mathrm{i})\right)$ and entropy $\left(\Delta \mathrm{S}_{\text {conf }}(\mathrm{i})\right)$ differences between the major and $\mathrm{i}^{\text {th }}$ minor conformation were obtained by fitting $\Delta \mathrm{G}_{\text {conf }}(\mathrm{i})$ as a function of temperature to the following equation,

$$
\Delta \mathrm{G}_{\text {conf }}(\mathrm{i})=\Delta \mathrm{H}_{\text {conf }}(\mathrm{i})-\mathrm{T} \Delta \mathrm{S}_{\text {conf }}(\mathrm{i}) \#(15)
$$

Errors in $\Delta \mathrm{H}_{\text {conf }}(\mathrm{i})$ and $\Delta \mathrm{S}_{\text {conf }}(\mathrm{i})$ were determined using a Monte-Carlo procedure. In particular, $\Delta \mathrm{G}_{\text {conf }}(\mathrm{i})$ for each point on the $\Delta \mathrm{G}_{\text {conf }}(\mathrm{i})$ vs. $\mathrm{T}$ plot was sampled from a Gaussian with mean and standard deviation equal to the mean value and error of the measured $\Delta \mathrm{G}_{\text {conf }}(\mathrm{i})$ values. Following gaussian sampling of all points on the plot, linear regression was performed to fit for $\Delta \mathrm{H}_{\text {conf }}(\mathrm{i})$ and $\Delta \mathrm{S}_{\text {conf }}(\mathrm{i})$. The procedure was repeated 10,000 times, and the mean and standard deviation of the resulting $\Delta \mathrm{H}_{\text {conf }}$ (i) and $\Delta \mathrm{S}_{\text {conf }}$ (i) distributions were set to be equal to the mean value and error of $\Delta \mathrm{H}_{\text {conf }}$ (i) and $\Delta \mathrm{S}_{\text {conf }}$ (i). The region spanned by the family of straight lines thus obtained is colored blue in Extended Data Fig. 11.

Given conformational equilibria for the melting of WT and Mut nucleic acids, we will have the following equation according to Fig. 1d,

$$
\Delta \mathrm{G}_{\text {conf }}(\mathrm{i})=\left(\Delta \mathrm{G}_{\text {melt }, \mathrm{WT}}+\Delta \mathrm{G}_{\mathrm{ss}(\text { Mut }-\mathrm{WT})}\right)-\left(\Delta \mathrm{G}_{\mathrm{i}(\text { Mut }-\mathrm{WT})}+\Delta \mathrm{G}_{\text {melt }, \text { Mut }}\right)
$$




$$
=\left(\Delta \mathrm{G}_{\text {melt }, \mathrm{WT}}-\Delta \mathrm{G}_{\text {melt }, \text { Mut }}\right)+\left(\Delta \mathrm{G}_{\mathrm{ss}(\text { Mut }-\mathrm{WT})}-\Delta \mathrm{G}_{\mathrm{i}(\text { Mut-WT })}\right) \#(16)
$$

where $\Delta \mathrm{G}_{\text {melt,WT }}$ and $\Delta \mathrm{G}_{\text {melt,Mut }}$ are the melting energies of the folded WT and Mut species, $\Delta \mathrm{G}_{\mathrm{ss}(\mathrm{Mut}-\mathrm{WT})}$ and $\Delta \mathrm{G}_{\mathrm{i}(\mathrm{Mut}-\mathrm{WT})}$ are the free energies of modifying (or mutating) the melted single stranded and the folded $i^{\text {th }}$ minor conformation, respectively. We also define,

$$
\begin{gathered}
\Delta \Delta \mathrm{G}_{\text {melt }}(\mathrm{i})=\Delta \mathrm{G}_{\text {melt,WT }}-\Delta \mathrm{G}_{\text {melt,Mut }} \#(17) \\
\mathrm{c}(\mathrm{i})=\Delta \mathrm{G}_{\mathrm{ss}(\text { Mut-WT })}-\Delta \mathrm{G}_{\mathrm{i}(\text { Mut-WT })} \#(18) \\
\Delta \Delta \mathrm{G}_{\text {delta-Melt }}(\mathrm{i})=\Delta \Delta \mathrm{G}_{\text {melt }}(\mathrm{i})+\mathrm{c}(\mathrm{i}) \#(19)
\end{gathered}
$$

where $\Delta \Delta \mathrm{G}_{\text {melt }}(\mathrm{i})$ is the difference in melting energies of the WT and Mut species, and $c(i)$ is the difference in free energies to modify (or mutate) the melted single-stranded (ss) and folded $\mathrm{i}^{\text {th }}$ minor species. Thus, $\Delta \mathrm{G}_{\text {conf }}(\mathrm{i})$ can be expressed as follows,

$$
\Delta \mathrm{G}_{\text {conf }}(\mathrm{i})=\Delta \Delta \mathrm{G}_{\text {delta-Melt }}(\mathrm{i})=\Delta \Delta \mathrm{G}_{\text {melt }}(\mathrm{i})+\mathrm{c}(\mathrm{i}) \#(20)
$$

Errors in $\Delta \Delta \mathrm{G}_{\text {melt }}$ (i) were determined by propagating the errors in $\Delta \mathrm{G}_{\text {melt,WT }}$ and $\Delta \mathrm{G}_{\text {melt,Mut }}$ obtained from UV melting measurements. The error in c(i) was determined using a Monte-Carlo scheme as described below.

All the calibration curves of $\Delta \mathrm{G}_{\text {conf }}(\mathrm{i})$ versus $\Delta \Delta \mathrm{G}_{\text {melt }}(\mathrm{i})$ were linearly fit assuming slope $=1$ using linear regression with Monte-Carlo iterations. In particular, each point 
on the $\Delta \mathrm{G}_{\text {conf }}$ (i) vs. $\Delta \Delta \mathrm{G}_{\text {melt }}$ (i) correlation plot was sampled from a gaussian with mean and standard deviation equal to the mean value and error of the measured $\Delta \mathrm{G}_{\text {conf }}$ (i) and $\Delta \Delta \mathrm{G}_{\text {melt }}(\mathrm{i})$ values along the $\mathrm{y}$ and $\mathrm{x}$ axes, respectively. Following gaussian sampling of all points on the plot, linear regression with a unit slope was performed to fit for c(i). The procedure was repeated 10,000 times, and the mean and standard deviation of the resulting $\mathrm{c}(\mathrm{i})$ distribution was set to be equal to the mean and error of $\mathrm{c}(\mathrm{i})$. The region spanned by the family of straight lines thus obtained is colored blue in Figs. $2 b$, $d$ and f, and $3 b$. The errors in $\Delta \Delta \mathrm{G}_{\text {delta-Melt }}$ (i) were obtained by propagating the errors in $\Delta \Delta \mathrm{G}_{\text {melt }}(\mathrm{i})$ and $\mathrm{c}(\mathrm{i})$. The Pearson's correlation coefficient $(r)$ as well as the root mean square of error (RMSE) between $\Delta \mathrm{G}_{\text {conf }}(\mathrm{i})$ and $\Delta \Delta \mathrm{G}_{\text {delta-Melt }}(\mathrm{i})=\Delta \Delta \mathrm{G}_{\text {melt }}(\mathrm{i})+\mathrm{c}(\mathrm{i})$ are reported (Figs. 2b, d, f, and $3 b$ ) for each comparison. A detailed discussion of the physical meaning of the intercept c(i) has been provided in Supplementary Note 1.

For TAR, UV and NMR measurements performed in the presence or absence of $1 \mathrm{mM} \mathrm{Mg}^{2+}$ were used to obtain differences in $\Delta \mathrm{G}_{\text {conf }}$ (i) and $\Delta \Delta \mathrm{G}_{\text {melt }}$ (i) as defined below,

$$
\begin{aligned}
\Delta \Delta \mathrm{G}_{\text {conf }} & =\Delta \mathrm{G}_{\text {conf }}\left(+1 \mathrm{mM} \mathrm{Mg}^{2+}\right)-\Delta \mathrm{G}_{\text {conf }}\left(-1 \mathrm{mM} \mathrm{Mg}^{2+}\right) \#(21) \\
\Delta \Delta \Delta \mathrm{G}_{\text {melt }} & =\Delta \Delta \mathrm{G}_{\text {melt }}\left(+1 \mathrm{mM} \mathrm{Mg}^{2+}\right)-\Delta \Delta \mathrm{G}_{\text {melt }}\left(-1 \mathrm{mM} \mathrm{Mg}^{2+}\right) \#(2)
\end{aligned}
$$

Errors in $\Delta \Delta \mathrm{G}_{\text {conf }}$ and $\Delta \Delta \Delta \mathrm{G}_{\text {melt }}$ were obtained by propagating errors in $\Delta \mathrm{G}_{\text {conf }}$ (i) and $\Delta \Delta \mathrm{G}_{\text {melt }}(\mathrm{i})$, obtained as described above. 
Given that the enthalpy and entropy change are also state variables in a manner analogous to the free energy, equations analogous to Equation 20 above, can also be written for them.

$$
\begin{gathered}
\Delta \mathrm{H}_{\text {conf }}(\mathrm{i})=\Delta \Delta \mathrm{H}_{\text {melt }}(\mathrm{i})+\mathrm{c}_{\text {Enthalpy }}(\mathrm{i}) \#(23) \\
\Delta \mathrm{S}_{\text {conf }}(\mathrm{i})=\Delta \Delta \mathrm{S}_{\text {melt }}(\mathrm{i})+\mathrm{c}_{\text {Entropy }}(\mathrm{i}) \#(24)
\end{gathered}
$$

Errors in $\Delta \Delta \mathrm{H}_{\text {melt }}(\mathrm{i})$ and $\Delta \Delta \mathrm{S}_{\text {melt }}$ (i) were determined by propagating the errors in $\Delta \mathrm{H}_{\text {melt,WT }}$ and $\Delta \mathrm{H}_{\text {melt,Mut }}$, and $\Delta \mathrm{S}_{\text {melt,WT }}$ and $\Delta \mathrm{S}_{\text {melt,Mut }}$, obtained from UV melting measurements, as described above. A comparative analysis of enthalpy and entropy values obtained from NMR and delta-Melt is provided in Extended Data Fig. 11 and Supplementary Note 3.

\section{Calculation of the energetics of Hoogsteen cooperativity}

Hoogsteen cooperativity can be quantified by the gained free energy $\left(\Delta \mathrm{G}_{\text {coop }}\right)$ of forming tandem Hoogsteen bps at two adjacent sites $(\mathrm{HG} 1+2)$ relative to forming Hoogsteen bps at each site (HG1 and HG2) independent of each other. $\Delta \mathrm{G}_{\text {coop }}$ is defined by the following equation,

$$
\Delta \mathrm{G}_{\text {coop }}=\Delta \mathrm{G}_{\text {conf }}(\mathrm{HG} 1)+\Delta \mathrm{G}_{\text {conf }}(\mathrm{HG} 2)-\Delta \mathrm{G}_{\text {conf }}(\mathrm{HG} 1+2) \#(25)
$$

Substituting $\Delta \mathrm{G}_{\text {conf }}(\mathrm{i})=\Delta \Delta \mathrm{G}_{\text {melt }}(\mathrm{i})+\mathrm{c}(\mathrm{i})($ Equation 20) to Equation 25 above yields, 


$$
\begin{aligned}
& \Delta \mathrm{G}_{\text {coop }}=\left(\Delta \Delta \mathrm{G}_{\text {melt }}(\mathrm{HG} 1)+\mathrm{c}(\mathrm{HG} 1)\right)+\left(\Delta \Delta \mathrm{G}_{\text {melt }}(\mathrm{HG} 2)+\mathrm{c}(\mathrm{HG} 2)\right)-\left(\Delta \Delta \mathrm{G}_{\text {melt }}(\mathrm{HG} 1+2)\right. \\
& +\mathrm{c}(\mathrm{HG} 1+2)) \\
& =\left(\Delta \Delta \mathrm{G}_{\text {melt }}(\mathrm{HG} 1)+\Delta \Delta \mathrm{G}_{\text {melt }}(\mathrm{HG} 2)-\Delta \Delta \mathrm{G}_{\text {melt }}(\mathrm{HG} 1+2)\right) \\
& \quad+(\mathrm{c}(\mathrm{HG} 1)+\mathrm{c}(\mathrm{HG} 2)-\mathrm{c}(\mathrm{HG} 1+2)) \#(26)
\end{aligned}
$$

We also define,

$$
\begin{gathered}
\text { Coop }_{\text {melt }}=\Delta \Delta \mathrm{G}_{\text {melt }}(\mathrm{HG} 1)+\Delta \Delta \mathrm{G}_{\text {melt }}(\mathrm{HG} 2)-\Delta \Delta \mathrm{G}_{\text {melt }}(\mathrm{HG} 1+2) \#(27) \\
\text { Coop }_{\text {offset }}=\mathrm{c}(\mathrm{HG} 1)+\mathrm{c}(\mathrm{HG} 2)-\mathrm{c}(\mathrm{HG} 1+2) \#(28)
\end{gathered}
$$

Therefore, we have

$$
\Delta \mathrm{G}_{\text {coop }}=\text { Coop }_{\text {melt }}+\text { Coop }_{\text {offset }} \#(29)
$$

The Coop melt $_{\text {term }}$ was determined using delta-Melt by using duplexes containing $N^{1}$ methylated purines at tandem bps, and their singly methylated counterparts (Fig. $2 \mathrm{~h}$, Extended Data Fig. 9). Errors in Coopmelt were obtained by propagating the errors in $\Delta \Delta \mathrm{G}_{\text {melt }}$ (i) values obtained as described above. In a manner analogous to defining cooperativity of Hoogsteen bp formation at two adjacent bps, we can also define cooperativity of forming Hoogsteen bps at three adjacent bps as follows

$$
\Delta \mathrm{G}_{\text {coop }}=\text { Coop }_{\text {melt }}+\text { Coop }_{\text {offset }} \#(30)
$$


where Coop melt and Coop offset are given by

$$
\begin{gathered}
\text { Coop }_{\text {melt }}=\Delta \Delta \mathrm{G}_{\text {melt }}(\mathrm{HG} 1)+\Delta \Delta \mathrm{G}_{\text {melt }}(\mathrm{HG} 2)+\Delta \Delta \mathrm{G}_{\text {melt }}(\mathrm{HG} 3)-\Delta \Delta \mathrm{G}_{\text {melt }}(\mathrm{HG} 1+2+3) \#(31) \\
\text { Coop }_{\text {offset }}=\mathrm{c}(\mathrm{HG} 1)+\mathrm{c}(\mathrm{HG} 2)+\mathrm{c}(\mathrm{HG} 3)-\mathrm{c}(\mathrm{HG} 1+2+3) \#(32)
\end{gathered}
$$

True estimation of Hoogsteen cooperativity requires knowledge of Coop offset. However, if we assume the offset term of double Hoogsteen $c(H G 1+2)$ and triple Hoogsteen $c($ HG1 $+2+3)$ is small, in a manner analogous to single Hoogsteen (Fig. $2 d$, $f$ and Supplementary Note 1), we will approximately have

$$
\Delta \mathrm{G}_{\text {coop }} \sim \text { Coop }_{\text {melt }} \#(33)
$$

\section{Acknowledgements}

We would like to thank all members of the Al-Hashimi lab for critical input. We would also like to thank Dr. Richard Brennan (Duke University, USA) for providing access to the UV spectrophotometer for the UV melts performed in this study and Dr. Christopher Kreutz (University of Innsbruck, Austria) for providing us site-specifically labeled RNA phosphoramidites. The research in this study was funded by the US National Institutes of Health grants R01GM089846 and a Mathers Foundation grant to H.M.A.

\section{Author Contributions}

A.R., H.S., Y.X. and H.M.A. conceived the project and experimental design. A.R., H.S., Y.X., B.L. H.A. and H.Z. prepared NMR samples, and collected NMR data with 
assistance from I.J.K. A.R., H.S., B.L., Y.X., H.A. prepared samples for UV melting and performed the experiments. A.R., H.S., Y.X. and H.M.A. wrote the manuscript with critical input from all co-authors.

\section{Competing interests}

The authors declare no competing interests.

\section{References}

1. Ganser, L.R., Kelly, M.L., Herschlag, D. \& Al-Hashimi, H.M. The roles of structural dynamics in the cellular functions of RNAs. Nat Rev Mol Cell Biol 20, 474-489 (2019).

2. Afek, A. et al. DNA mismatches reveal conformational penalties in protein-DNA recognition. Nature 587, 291-296 (2020).

3. Fischer, M., Coleman, R.G., Fraser, J.S. \& Shoichet, B.K. Incorporation of protein flexibility and conformational energy penalties in docking screens to improve ligand discovery. Nat Chem 6, 575-583 (2014).

4. $\quad$ Palmer, A.G., 3rd \& Koss, H. Chemical Exchange. Methods Enzymo/615, 177236 (2019).

5. Schroeder, S.J. \& Turner, D.H. Optical melting measurements of nucleic acid thermodynamics. Methods Enzymol 468, 371-387 (2009).

6. Colizzi, F. et al. Asymmetric base-pair opening drives helicase unwinding dynamics. Proc Natl Acad Sci U S A 116, 22471-22477 (2019).

7. Gueron, M. \& Leroy, J.L. Studies of base pair kinetics by NMR measurement of proton exchange. Methods Enzymol 261, 383-413 (1995).

8. Priyakumar, U.D. \& Mackerell, A.D., Jr. Computational approaches for investigating base flipping in oligonucleotides. Chem Rev 106, 489-505 (2006).

9. Nikolova, E.N. et al. Transient Hoogsteen base pairs in canonical duplex DNA. Nature 470, 498-502 (2011).

10. Hoogsteen, K. The structure of crystals containing a hydrogen-bonded complex of 1-methylthymine and 9-methyladenine. Acta Crystallographica 12, 822-823 (1959).

11. Golovenko, D. et al. New Insights into the Role of DNA Shape on Its Recognition by p53 Proteins. Structure 26, 1237-1250 e1236 (2018).

12. $\mathrm{Xu}, \mathrm{Y}$. et al. Hoogsteen base pairs increase the susceptibility of double-stranded DNA to cytotoxic damage. J Biol Chem (2020). 
13. Shi, H. et al. Atomic structures of excited state A-T Hoogsteen base pairs in duplex DNA by combining NMR relaxation dispersion, mutagenesis, and chemical shift calculations. J Biomol NMR 70, 229-244 (2018).

14. Zhou, H. et al. m(1)A and $m(1) G$ disrupt A-RNA structure through the intrinsic instability of Hoogsteen base pairs. Nat Struct Mol Biol 23, 803-810 (2016).

15. Alexandrov, L.B. et al. Signatures of mutational processes in human cancer. Nature 500, 415-421 (2013).

16. Zhou, H. et al. New insights into Hoogsteen base pairs in DNA duplexes from a structure-based survey. Nucleic Acids Res 43, 3420-3433 (2015).

17. Gilbert, D.E. \& Feigon, J. Proton NMR study of the [d(ACGTATACGT)]22echinomycin complex: conformational changes between echinomycin binding sites. Nucleic Acids Res 20, 2411-2420 (1992).

18. Lee, J., Dethoff, E.A. \& Al-Hashimi, H.M. Invisible RNA state dynamically couples distant motifs. Proc Natl Acad Sci U S A 111, 9485-9490 (2014).

19. Rangadurai, A., Szymaski, E.S., Kimsey, I.J., Shi, H. \& Al-Hashimi, H.M. Characterizing micro-to-millisecond chemical exchange in nucleic acids using offresonance R1rho relaxation dispersion. Prog Nucl Magn Reson Spectrosc 112113, 55-102 (2019).

20. Meyer, K.D. \& Jaffrey, S.R. The dynamic epitranscriptome: N6-methyladenosine and gene expression control. Nat Rev Mol Cell Biol 15, 313-326 (2014).

21. Liu, B. et al. A quantitative model predicts how m6A reshapes the kinetic landscape of nucleic acid hybridization and conformational transitions. biorXiv (2020).

22. Shi, H. et al. NMR Chemical Exchange Measurements Reveal That N(6)Methyladenosine Slows RNA Annealing. J Am Chem Soc 141, 19988-19993 (2019).

23. Bae, J.H., Fang, J.Z. \& Zhang, D.Y. High-throughput methods for measuring DNA thermodynamics. Nucleic Acids Res 48, e89 (2020).

24. Szulik, M.W., Voehler, M. \& Stone, M.P. NMR analysis of base-pair opening kinetics in DNA. Curr Protoc Nucleic Acid Chem 59, 720 21-18 (2014).

25. Chen, C. \& Russu, I.M. Sequence-dependence of the energetics of opening of at basepairs in DNA. Biophys J 87, 2545-2551 (2004).

26. Basanta-Sanchez, M., Temple, S., Ansari, S.A., D'Amico, A. \& Agris, P.F. Attomole quantification and global profile of RNA modifications: Epitranscriptome of human neural stem cells. Nucleic Acids Res 44, e26 (2016).

27. Macon, J.B. \& Wolfenden, R. 1-Methyladenosine. Dimroth rearrangement and reversible reduction. Biochemistry 7, 3453-3458 (1968).

28. Zimmer, D.P. \& Crothers, D.M. NMR of enzymatically synthesized uniformly 13C15N-labeled DNA oligonucleotides. Proc Natl Acad Sci U S A 92, 3091-3095 (1995).

29. Juen, M.A. et al. Excited States of Nucleic Acids Probed by Proton Relaxation Dispersion NMR Spectroscopy. Angew Chem Int Ed Engl 55, 12008-12012 (2016). 
30. Strebitzer, E., Nussbaumer, F., Kremser, J., Tollinger, M. \& Kreutz, C. Studying sparsely populated conformational states in RNA combining chemical synthesis and solution NMR spectroscopy. Methods 148, 39-47 (2018).

31. Neuner, S., Santner, T., Kreutz, C. \& Micura, R. The "Speedy" Synthesis of Atom-Specific (15)N Imino/Amido-Labeled RNA. Chemistry 21, 11634-11643 (2015).

32. Wunderlich, C.H. et al. Synthesis of (6-(13)C)pyrimidine nucleotides as spinlabels for RNA dynamics. J Am Chem Soc 134, 7558-7569 (2012).

33. Xu, Y., McSally, J., Andricioaei, I. \& Al-Hashimi, H.M. Modulation of Hoogsteen dynamics on DNA recognition. Nat Commun 9, 1473 (2018).

34. Liu, B. et al. A potentially abundant junctional RNA motif stabilized by $\mathrm{m}(6) \mathrm{A}$ and Mg(2). Nat Commun 9, 2761 (2018).

35. Dethoff, E.A., Petzold, K., Chugh, J., Casiano-Negroni, A. \& Al-Hashimi, H.M. Visualizing transient low-populated structures of RNA. Nature 491, 724-728 (2012).

36. Leroy, J.L., Kochoyan, M., Huynh-Dinh, T. \& Gueron, M. Characterization of base-pair opening in deoxynucleotide duplexes using catalyzed exchange of the imino proton. J Mol Biol 200, 223-238 (1988).

37. Sathyamoorthy, B. et al. Insights into Watson-Crick/Hoogsteen breathing dynamics and damage repair from the solution structure and dynamic ensemble of DNA duplexes containing m1A. Nucleic Acids Res 45, 5586-5601 (2017).

38. Nikolova, E.N., Gottardo, F.L. \& Al-Hashimi, H.M. Probing transient Hoogsteen hydrogen bonds in canonical duplex DNA using NMR relaxation dispersion and single-atom substitution. J Am Chem Soc 134, 3667-3670 (2012).

39. Nikolova, E.N., Goh, G.B., Brooks, C.L., 3rd \& Al-Hashimi, H.M. Characterizing the protonation state of cytosine in transient G.C Hoogsteen base pairs in duplex DNA. J Am Chem Soc 135, 6766-6769 (2013).

40. Delaglio, F. et al. NMRPipe: a multidimensional spectral processing system based on UNIX pipes. J Biomol NMR 6, 277-293 (1995).

41. Hansen, A.L., Nikolova, E.N., Casiano-Negroni, A. \& Al-Hashimi, H.M. Extending the range of microsecond-to-millisecond chemical exchange detected in labeled and unlabeled nucleic acids by selective carbon R(1rho) NMR spectroscopy. J Am Chem Soc 131, 3818-3819 (2009).

42. Korzhnev, D.M., Orekhov, V.Y. \& Kay, L.E. Off-resonance R(1rho) NMR studies of exchange dynamics in proteins with low spin-lock fields: an application to a Fyn SH3 domain. J Am Chem Soc 127, 713-721 (2005).

43. Kimsey, I.J., Petzold, K., Sathyamoorthy, B., Stein, Z.W. \& Al-Hashimi, H.M. Visualizing transient Watson-Crick-like mispairs in DNA and RNA duplexes. Nature 519, 315-320 (2015).

44. Rangadurai, A., Szymanski, E.S., Kimsey, I., Shi, H. \& Al-Hashimi, H.M. Probing conformational transitions towards mutagenic Watson-Crick-like G.T mismatches using off-resonance sugar carbon R1rho relaxation dispersion. J Biomol NMR 74, 457-471 (2020). 
45. Bothe, J.R., Stein, Z.W. \& Al-Hashimi, H.M. Evaluating the uncertainty in exchange parameters determined from off-resonance R1rho relaxation dispersion for systems in fast exchange. J Magn Reson 244, 18-29 (2014).

46. Alvey, H.S., Gottardo, F.L., Nikolova, E.N. \& Al-Hashimi, H.M. Widespread transient Hoogsteen base pairs in canonical duplex DNA with variable energetics. Nat Commun 5, 4786 (2014).

47. Zhao, B., Hansen, A.L. \& Zhang, Q. Characterizing slow chemical exchange in nucleic acids by carbon CEST and low spin-lock field R(1rho) NMR spectroscopy. J Am Chem Soc 136, 20-23 (2014).

48. Rangadurai, A., Shi, H. \& Al-Hashimi, H.M. Extending the Sensitivity of CEST NMR Spectroscopy to Micro-to-Millisecond Dynamics in Nucleic Acids Using High-Power Radio-Frequency Fields. Angew Chem Int Ed Engl 59, 11262-11266 (2020).

49. Bouvignies, G. \& Kay, L.E. A 2D (1)(3)C-CEST experiment for studying slowly exchanging protein systems using methyl probes: an application to protein folding. J Biomol NMR 53, 303-310 (2012).

50. Gueron, M., Kochoyan, M. \& Leroy, J.L. A single mode of DNA base-pair opening drives imino proton exchange. Nature 328, 89-92 (1987).

51. Abou Assi, H. et al. 2-O-Methylation can increase the abundance and lifetime of alternative RNA conformational states. Nucleic Acids Res, In Press (2020).

52. Klostermeier, D. \& Millar, D.P. Helical junctions as determinants for RNA folding: origin of tertiary structure stability of the hairpin ribozyme. Biochemistry 39 , 12970-12978 (2000). 